\title{
A New Approach in Pressure Transient Analysis Part I: Improved Diagnosis of Flow Regimes in Oil and Gas Wells
}

\section{Biu Victor $\mathrm{T}^{\star}$ and Zheng Shi-Yi}

London South Bank University, United Kingdom

\begin{abstract}
One important limitation of pressure derivatives is diagnosing flow regimes in wells with high water cut and flowing conditions (Drawdown) because the well production are never stable due to surface operating constraint including multiphase metering problem and fluid compressibility, hence most drawdown are not easily interpretable due to noisy data. In some cases where the data are useful, the derivative data are always noisy and difficult to interpret, resulting in the application of deconvolution and various smoothing techniques to obtain a perceived representative model which often time might not.

This paper introduces a new statistical method for diagnosing flow regime for both flowing and shut-in conditions. The method utilize the second differencing of pressure and time parameters since pressure change and subsurface flow rate is non-stationary and then integrate the residual pressure differences using simple statistical tools such as sum of square error SSE, moving average MA and covariance of data to formulate the statistical derivative model. The model is tested with constant pressure, constant rate conditions and also in well with high water production

Results from three scenarios investigated shows the statistical derivative display distinctive radial flow fingerprint as the conventional pressure derivative with clear reservoir features revealed with high degree of accuracy. It demonstrated that for high water production well, a good radial stabilization can be identified for good permeability estimation without smoothing the data. It also showed that in all three scenarios, the drawdown radial fingerprint can be replicated in the build-up pressure responses, hence a good match of the data. The approach also reduces the derivative noise in the radial flowing period for better interpretation of flow regimes.
\end{abstract}

Keywords: Pressure transient analysis; Drawdown; Build-up test; Flow regimes; Derivatives; Statdev; StatExp; Stattdev; Statddev

\section{Nomenclature}

P: Pressure psi

$\mathrm{T}$ : Temperature

r: Radius $\mathrm{ft}$

k: Permeability md

$\varnothing$ : Porosity fraction

$\mu$ : Viscosity cp

t: Time hrs

q: Production rate bbl/day

B: Formation volume factor $\mathrm{rb} / \mathrm{Stb}$

Ct: Total compressibility psi-1

rw: Wellbore radius $\mathrm{ft}$

$\Delta \mathrm{p}$ : Change in pressure psia

h: Formation thickness $\mathrm{ft}$

$\mathrm{x}$ : Observed or sample values of a variable

$y$ : Observed or sample values of a variable

A: Drainage Area acres; CA: Area compressibility psi-1

S: Skin dimensionless
Pwf: Bottom hole flowing pressure psi

Pi: Initial Pressure psi

Z: Difference between two point/ time series

i: Subscript of an observed variable

c: Subscript of a calculated variable

STEYX: SSE of data point

$\mathrm{n}$ : Number of data point

Cov: Covariance of data point

$\delta$ : Standard deviation

tp: Cumulative production time

Cs: Wellbore storage constant

$\bar{x}$ : Mean of data point.

*Corresponding author: Biu Victor T, London South Bank University, United Kingdom, Tel: +44 207815 7815; E-mail: biut@Isbu.ac.uk

Received June 20, 2015; Accepted July 16, 2015; Published July 26, 2015

Citation: Victor BT, Shi-Yi Z Shi-Yi Z (2015) A New Approach in Pressure Transient Analysis Part I: Improved Diagnosis of Flow Regimes in Oil and Gas Wells. J Pet Environ Biotechnol 6: 244. doi:10.4172/2157-7463.1000244

Copyright: ( 2015 Victor BT, et al. This is an open-access article distributed under the terms of the Creative Commons Attribution License, which permits unrestricted use, distribution, and reproduction in any medium, provided the original author and source are credited. 


\begin{abstract}
Abbreviation: Statdiff: Statistical Difference; Statdev: Statistical Deviation; Statdev (SQR): Square-Root of Statistical Deviation; StatSSE: Statistical Sum of Square Error; Statdiv: Statistical Divisible; Stdev: Standard Deviation in Excel sheet; VEMST: Victor Emmanuel Mike Statistical Techniques; SSE: Sum of Square Error; MSE: Mean Square Error; PPD: Primary Pressure Derivative Function; WBHP: Well Bottom Hole Pressure; LGR: Local Grid Refinement
\end{abstract}

\section{Introduction}

Subsurface geology and hydrology are heterogeneous, complex, and difficult to characterize (e.g. Neumann and Di Federico, 2003); hence the concept of porous media flow, heat conduction, neutron diffusion, or elastic waves have being used by hydrology researchers to capture the fluid flow behavior using complex mathematical equations such as diffusion and advection-dispersion developed into partial differential equation (PDE) often in pressure term. Transient, confined groundwater flow in an elastic aquifer is governed by this diffusion PDE with generalized linear and non-linear problems that can often be approximated adequately by linearizing with Laplace transformation using some boundary conditions and assumption. Typically, the analytical solution developed from simplified set of conditions solves the groundwater flow equation and the pressure derivative term of the analytical solution is used to diagnose the transient and pseudo steady state flowing conditions. Likewise the same procedure or workflow is applicable for modeling fluid flow behavior in a typical oil, water and gas reservoir.

To understand, analyze and predict the movement of subsurface fluid such as groundwater used for geothermal energy generation, researchers relies on the measurement, analysis and interpretation of aquifer parameters such as pressures data which is used to estimates aquifer properties like permeability, reservoir size, heterogeneity and initial pressure [1].

Flow in a reservoir is often characterized as either transient or boundary-dominated. Transient flow occurs when the reservoir boundaries have not been felt in which the reservoir is said to be infiniteacting. This occurs in the early life of a well. At this point, the size of the reservoir has no effect on the well productivity and performance, and from analysis of pressure or production data, nothing can be deduced about the reservoir size. Transient flow forms the basis of a domain of reservoir engineering called Pressure Transient Analysis (PTA), also known as welltest interpretation which is used extensively for volumetric estimation, well deliverability, reservoir characterization and efficient field management.

However its accuracy depends on precise analysis and integrated reservoir studies. For over 4 decades, welltesting has been transformed from a level mainly interested in determining a well's productivity to a sophisticated discipline capable of characterizing the reservoir geometry, boundary and heterogeneity [2-8].

Pressure transient analysis depends strongly on complex equations of fluid flow for a well flowing at a constant rate. At the initial conditions, the flow regime is transient, but when all the reservoir boundaries have been felt, the well flows at steady state (if a constant pressure boundary exists) or at pseudo-steady state (if all the boundaries are no-flow boundaries). It is well-known that during pseudo-steady state, the pressure throughout the reservoir declines at the same rate, and the reservoir is assumed to be acting like a tank. The theory of pseudo-steady state is applicable to a situation where the well is flowing at a constant flow state; if there is a single well which is producing, the pressure distribution of this well as time changes is constant. Invariably a well depicts infinite-acting reservoir condition if the boundary response has not been felt but immediately the pressure perturbation hits the boundary, the well is no longer infinite-acting in nature but in pseudo steady state flowing condition. Similarly, for an enclosed reservoir system with a single producing well, the pressure distribution of this well can be described as boundary dominated which is pseudo-steady in nature and occur when the pressure hits the boundary. Modeling the processes that governs these flowing conditions entails complex mathematical equations that have been simplified over the years by researchers.

Muskat [9] and Theis [10] introduced the fluid flow diffusivity model using only one fraction of data to mimic fluid flow in producing water well considering the fluid compressibility and also deformation of the aquifer behaviour. Since then, several researches have been done to simplify the fluid flow diffusivity equation using linear and nonlinear solution. This pave way for the application of Miller [11] specialized pressure-time plot and several type curves starting from Agarwal [12], Ramey [13] and Gringarten [14] and many other in PTA.

However identification of the radial flow was still a difficult task for welltest specialist, reservoir engineers and petroleum engineering researchers before the early eighties until the emergence of the derivative approach. The derivative method which is the greatest breakthrough in welltest analysis was introduced by French Mathematician Bourdet [15]. It has remained the reference solution for identifying flow regime, boundary response and also for diagnosing complex reservoir features till date. This approach has helped to reduce the uncertainties surrounding the interpretation of welltest data because key regions of radial flow and boundary features have been adequately diagnosed. However due to the non-unique solution of the mathematical fluid flow equation, mostly in heterogeneous reservoir, most engineers in the industry are compelled to use analytical model and typecurve solution to match complex model which is often times not realistic. Assumptions made are ignored while pursuing a perfect match and result obtained from this approach are often misleading [16].

This marks the beginning of numerical welltesting in the industry by Zheng [16]. This approach started from the early 1990s [17-21] More advances were made by Zheng [16] providing more solutions to the non-unique solution problems in heterogeneous reservoir through numerical welltesting, thereby promoting its application. More papers have been published by researchers on the subject reflecting the advancement of numerical well testing and its application in solving various reservoirs engineering practical problem.

One of the main limitations of the pressure derivative is that the measured pressure data must be constructed into derivative data, by means of numerical differentiation. Often time derivative data from real field are very noisy and difficult to interpret, resulting to various smoothing techniques developed by researcher on this subject. It is practically believed that, often smoothing of pressure derivative data alters the characteristics of the data.

Another limitation of the derivatives is diagnosing flow regimes in wells with high water production and also in flowing period of the test (Drawdown) because the well production is never stable. Surface operating constraint including multiphase metering problem and fluid compressibility makes it difficult to achieve stable or constant rate during test, hence most drawdown are not interpretable due to noisy data. In some cases where the data are useful, the derivative data are always noisy and difficult to interpret, resulting in the application of 
deconvolution and various smoothing techniques to obtain a perceived representative model which often time might not be.

However, in practice, each current method of transient data analysis has its own strengths and limitations with no single pressure and production data analysis method capable of handling all types of data and reservoir types with clear reliable result [22]. The log derivative and derivative type-curve which have remained reference flow regimes diagnostic tools for over four decades are the only unified approach for well-test interpretation and are applicable in a wide range of situations. This is an improvement to the first publication by Victor [23] in which the approach was tested only on buildup data.

\section{Theory of pressure transient analysis}

Pressure transient analysis is based on the radial diffusivity equation which relates pressure to time and drainage radius. The simplest solution to this equation is valid for a single well in an infinite reservoir. The radial diffusivity equation is given by:

$$
\frac{d^{2} P}{d r^{2}}+\frac{1}{r} \frac{d P}{d r}=\frac{1}{0.0002637} \frac{\varphi \mu c_{t}}{k} \frac{d P}{d t}
$$

Where the units of viscosity $\mu$ are in cp, permeability $\mathrm{k}$ is measured in $\mathrm{mD}$, pressure $\mathrm{P}$ in psi, radius $\mathrm{r}$ in $\mathrm{ft}$, compressibility $\mathrm{c}_{\mathrm{t}}$ as $\mathrm{psi}^{-1}$, and time $t$ in hours while porosity $\varphi$ is dimensionless. The solution to the radial diffusivity equation (1) enables the engineer, fluid flow specialist and the academic to perform a conventional analysis for various bottom-hole pressure tests. Unfortunately however, the assumptions made within the diffusivity solutions are not always applicable to all bottom-hole pressure tests.

As stated in the first publication of the statistical approach by Victor [23], "The diagnosis of the flow which appear as distinctive patterns in the pressure-derivative curve, is a vital point in welltest interpretations since each flow regime reflects the geometry of the flow streamlines in the tested formation, hence, for each flow regime identified, a set of well and/or reservoir parameters can be estimated using the region of the transient data that exhibits the characteristic pattern behavior". These flow regimes exhibit characteristic flow patterns, such as radial, spherical, linear and bilinear [24] and are recognized as a horizontal line, negative half slope, half slope and quarter slope on the pressure-derivative curve. This demonstrates that the log-log plot of the pressure-derivative is a powerful tool for model identification in pressure transient analysis [23].

The logarithm derivative function can be expressed as;

$\frac{d \Delta p}{d \ln t}=t \frac{d \Delta p}{d t}$

Horne [25] formulates a mathematical model for the derivative which is given as:

$$
\begin{aligned}
& \left(\frac{\partial p}{\partial \ln t}\right)=t\left(\frac{\partial p}{\partial p}\right)_{i}-A \\
& A=\frac{\ln \left(t_{i} / t_{i-k}\right) \Delta p_{i+j}}{\ln \left(t_{i+j} / t_{i}\right) \ln \left(t_{i+j} / t_{i-k}\right)}+\frac{\ln \left(t_{i+j} t_{i-k} / t_{i}{ }^{2}\right) \Delta p_{i}}{\ln \left(t_{i+j} / t_{i}\right) \ln \left(t_{i} / t_{i-k}\right)}-\frac{\ln \left(t_{i+j} / t_{i}\right) \Delta p_{i+k}}{\ln \left(t_{i} / t_{i-k}\right) \ln \left(t_{i+j} / t_{i-k}\right)}
\end{aligned}
$$

For situations where the production rates are varying, recovery data with changing sampling frequency have to be interpreted or there is time shift errors effect, the derivative diagnostic plot is conditionally used provided the data are pre-processed by a deconvolution technique. This paper presents the statistical derivative method which acts as a support for welltest interpretation on complex and varying frequency data.

\section{The statistical models}

The new methods tend to derive the pressure derivative functions $\frac{d \Delta p}{d t}=\frac{d\left(p_{i}-p_{w f}\right)}{d t}, \frac{d \Delta p}{d \ln t}=t \Delta p=\frac{t d \Delta p}{d t}$ using $1^{\text {st }}$ and $2^{\text {nd }}$ pressure and time differencing and statistical parameters. This is an improvement to the first publication by Victor et al. [23] in which the approach was limited to only buildup data and condition. As stated in the first publication, "the statistical models are derived from differencing method in time series analysis which is common in advanced statistical forecasting where it is often used to transform a non-stationary time series into a stationary time series". The statistical parameters used include standard error of the estimate (STEYX, SEE), covariance (COV), unexplained variation (SSE) which helped to provide both positive and negative relationship between pressure and time (high correlation) in order to mimic the pressure derivatives generated from differentiating the linear solution of the fluid flow diffusivity equation in radial systems. Also the residual of the variation in pressure and time is integrating in the statistical model using the SSE and SEE parameters.

The statistical approach utilized simple statistical tools such as the product and exponential of $1^{\text {st }}$ and $2^{\text {nd }}$ difference of a well bottom-hole flowing or shut-in pressure tied to the standard deviation and sum of square difference of this data to generate the statistical models such as Statdiv, StatSSE, Statdev, StatExp, Stattdev and Statddev which is then used as diagnostic tools to help identify possible key flow regimes for reservoir description and support the derivative approach for better interpretation of complex features $[23,26]$.

If $n$ values $P_{1}, P_{2} \ldots P_{n}$ of a time series are observed, the first difference of the time series values $\mathrm{P}_{1}, \mathrm{P}_{2} \ldots \mathrm{P}_{\mathrm{n}}$ are;

$\Delta P_{t}=P_{0}-P_{i}$

Where $\mathrm{i}=1,2,3 \ldots \mathrm{t}_{\mathrm{n}}$

$$
\operatorname{StatDiv}(i)=\frac{\Delta P_{i}}{P_{i}}
$$

And

$$
\begin{aligned}
& \operatorname{StatSSE}(i)=\left[\frac{\Delta P_{i}}{P_{2}}\right]^{\frac{\delta d e v}{\operatorname{SEE}}} \\
& \text { Where } \frac{\text { ddev }}{\operatorname{SEE}}=\left[\frac{\operatorname{STDEVP}(\operatorname{StatDiv}())}{\operatorname{STEYX}\left(\operatorname{StatDiv}(), \Delta^{2} P()\right)}\right] \text { and } \Delta^{2} P(i)=\Delta P(i+1)-\Delta P(1)
\end{aligned}
$$

Equation 5 and 6 are known as model A and B. These are similar to semilog pressure-time curve but are used for identifying flow regimes and calculation of wellbore and reservoir parameters to support the interpretation from the type-curve and derivatives methods. The idea is to keep it simple and also create room for improved reservoir properties estimation for better reservoir characterization [27].

The six models mimicking the log-log pressure derivative approach are derived using the steps below.

First the $1^{\text {st }}$ pressure and time differencing are obtained:

$$
\begin{aligned}
& \Delta P_{t}=P_{0}-P_{i} \\
& \Delta t_{t}=t_{i+1}-t_{i}
\end{aligned}
$$

Then the divided 1st differencing for pressure and time is derived:

$$
\Delta \operatorname{dev}(i)=\frac{\Delta P(i+1)}{\Delta P(2)}
$$




$$
\Delta t_{t}=\Delta t_{i} / \Delta t_{i+1}
$$

The residual for the pressure and time differencing are generated using the statistical functions such as standard deviation between data point:

$$
p d d(i)=\operatorname{SQRT}\left(\delta \Delta p t(i) x \operatorname{STDEV}\left(\Delta \operatorname{dev}(), \Delta^{2} P()\right)\right)
$$

To reduce the noise effect arising from the differencing, the square root of the standard deviation of the 1st differencing and the divided 1 st differencing for pressure is obtained:

$$
p d d(i)=\operatorname{SQRT}\left(\delta \Delta p t(i) x \operatorname{STDEV}\left(\Delta \operatorname{dev}(), \Delta^{2} P()\right)\right)
$$

Finally, the six statistical models for flow regime diagnosis are given as:

$$
\text { Model 1: } \operatorname{StatDev}(i)=\operatorname{SQRT}\left(p d d(i) x \Delta \operatorname{dev}(i) x \Delta^{2} P(i)\right)
$$

Model 2: The Exponential function

$$
\operatorname{StatExp}(i)=\operatorname{SQRT}\left(\operatorname{EXP}\left(\operatorname{SQRT}\left(\Delta^{2} P\right)\right)\right) x p d d(i) x \Delta^{2} P(i)
$$

Model 3: $\operatorname{StatdDev}(i)=\operatorname{SQRT}\left(p d d(i) x \Delta \operatorname{dev}(i) x \Delta^{2} P(i) x \Delta^{2} P(i)\right)$

Model 4: The Time function

$$
\operatorname{StattDev}(i)=\operatorname{STDEV}(\Delta t(i), \Delta t(i+1), \operatorname{StatDev}(i), \operatorname{StatDev}(i+1))
$$

Model 5:

$\operatorname{StatdDev}\left(\mathrm{i}^{0.4}=(\Delta \mathrm{p}(\mathrm{i}+1)-\Delta \mathrm{p}(\mathrm{i})) * \mathrm{pdd}(\mathrm{i}) * \frac{\Delta \operatorname{dev}(\mathrm{i})}{\Delta \mathrm{p}(\mathrm{i})} * \operatorname{Exp}\left(\frac{\Delta \mathrm{tt}(\mathrm{i})}{\Delta \mathrm{tt}(\mathrm{i}+1)}\right)+\sqrt{\left(\mathrm{tit1}^{2}{ }^{2}+\mathrm{t}_{\mathrm{i}}{ }^{2}\right)-\left(\mathrm{t}_{\mathrm{i}}{ }^{2}-\mathrm{t}_{\mathrm{i}-1}{ }^{2}\right.}\right) * \frac{\delta \mathrm{ppt}(\mathrm{i})}{\Delta \mathrm{p}(\mathrm{i})}$

Model 6:

$$
\operatorname{StatdDev}(\mathrm{i})^{2}=\left(\frac{\Delta \mathrm{p}(\mathrm{i}+1)}{\Delta \mathrm{p}(0)}\right) * \sqrt{\Delta \mathrm{p}(\mathrm{i})}+\operatorname{Exp}\left(\frac{\Delta \mathrm{tt}(\mathrm{i})}{\Delta \mathrm{tt}(\mathrm{i}+1)}\right) * \delta \Delta \mathrm{pt}(\mathrm{i}) * \operatorname{pdd}(\mathrm{i})
$$

In the three scenarios investigated, equations 17 and 18 are statistical models used for flow regime diagnosis. The log$\log$ of equations 13 to 18 are similar to $\log$-log derivatives used for identifying flow regimes. They are also used for calculation of wellbore and reservoir parameters in order to support the interpretation from the convention method or type-curve after the analysis of the log-log derivative plot.

Figure 1 is the stepwise workflow used for generating the statistical models Statdiv, StatSSE, Statdev, StatExp, Statddev and Stattdev for the semilog and log-log diagnostic responses in pressure transient analysis. Also Figure 2 shows the different statistical models generated from equation 13 to $18[28,29]$.

\section{Example}

Table 1 presents a summary of the well and reservoir synthetic data used for the tested build-up and drawdown simulated scenario with additional information given below. It is required to generate the bottomhole pressures and derivative, compare their diagnostic signatures.

\section{Assumption}

- Oil reservoir+Gas Cap, completed with one well.

- LGR was imposed around the well and far across to account for pressure changes

WBHP around the local grid refinement (wellbore) is output using Eclipse keywords. The following scenarios were evaluated:
a. Constant pressure solution
b. Constant rate solution

\section{c. High water production imposed on well}

Figure 3 shows the summary of the flowing and shut-in sequence for the 3 scenarios.

In scenario a, the bottomhole flowing pressure WBHP is fixed at 3500 psia and the well is allow to produce as much as possible. WBHP is measured from the LGR keyword in order to monitor the sharp changes in pressure around the wellbore. The ideal drawdown and build-up data were analyzed using the conventional and statistical methods.

The statistical derivative plot in Figure 4 shows a good radial stabilization after $1.0 \mathrm{hrs}$ for both (drawdown and buildup analysis) but with different dp' flat points. In addition, the late time effect is seen in the drawdown clearly indicating a change in mobility effect.

However in the convention derivative method, the log-log build-up plot depict similar radial stabilization fingerprint in the drawdown but noisy and continuous drop in the build-up derivative as seen in Figure 5. This feature differs with the drawdown scenario in the conventional method and the statistical method. In both approach no smoothing is allowed in order to capture the real data behavior

To test this approach with constant production rate solution, a fixed rate of 200 bopd is imposed on the well while the bottomhole flowing pressure is monitored and analyzed. No smoothing technique is applied as usual. In this scenario b, the statistical derivative log$\log$ plot shown in Figure 6 exhibit good radial stabilization after $1 \mathrm{~h}$ in both build-up and drawdown as in scenario a. This confirms that the radial flow effect starts at $1 \mathrm{~h}$. However, this feature is absent in the conventional method and slightly seen in the buildup derivative curveas shown in Figure 7.

One important limitation of the derivatives is diagnosing flow regimes in 2 phase fluid flow condition due to the fact that the drawdown are prompt to noisy data. To view the effect of 2 phase flow on the statistical derivative, a fixed bottomhole pressure of 1000 psia is imposed on the well and BSW starting from $20 \%$ increases to almost $70 \%$ during the drawdown test.

In this scenario, the radial stabilization is deferred to 3 hrs during the drawdown and 6 hrs for the buildup for the statistical derivative. The first $1 \mathrm{hrs}$ witness a flat line and change of mobility probably due to 2 phase fluid flow at the wellbore (gravity effect). Also a final radial flow for both buildup and drawdown is seen in Figure 8 after $10 \mathrm{~h}$. Nevertheless it is in line with the result from scenario a and b. However for the conventional method, a sharp drop in buildup derivative is seen after $1 \mathrm{hrs}$ with no radial stabilization as shown in Figure 9.

In this scenario, the derivative did not depict radial flow for both drawdown and buildup but indicates drop in derivative at late time which differs with scenario a and $b$ interpretation.

In summary, the statistical derivative has demonstrated that for high water production well, a good radial stabilization can be identified for good permeability estimation without smoothing the data. Also it has shown in all three scenarios that, the drawdown fingerprint can be replicated in the build-up pressure responses, hence a good match of the data [30-34].

A summary of the statistical versus conventional derivatives log$\log$ are shown for different reservoir and well conditions from Figure $10-26$. 
Citation: Victor BT, Shi-Yi Z (2015) A New Approach in Pressure Transient Analysis Part I: Improved Diagnosis of Flow Regimes in Oil and Gas Wells. J Pet Environ Biotechnol 6: 244. doi:10.4172/2157-7463.1000244

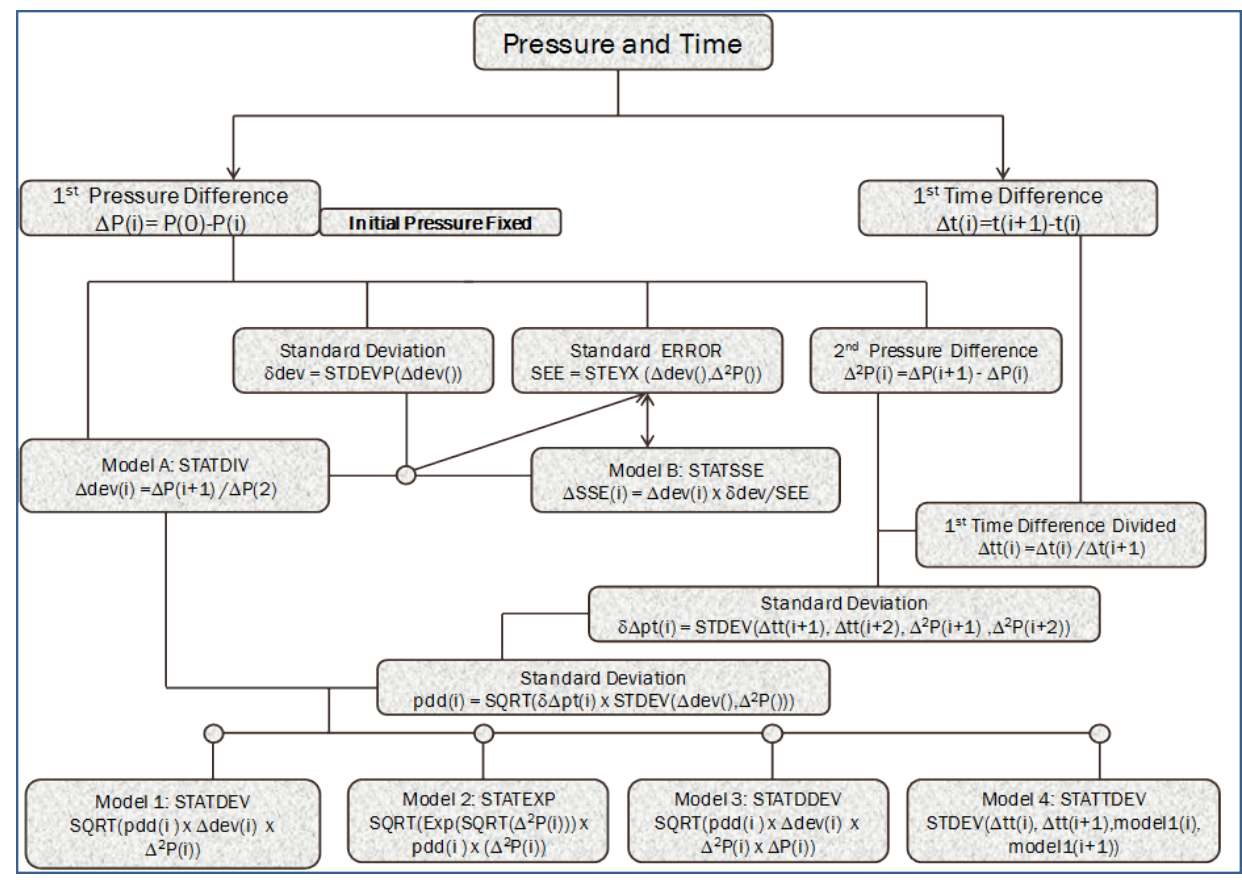

Figure 1: Workflow for statistical models formulation using pressure and time data.

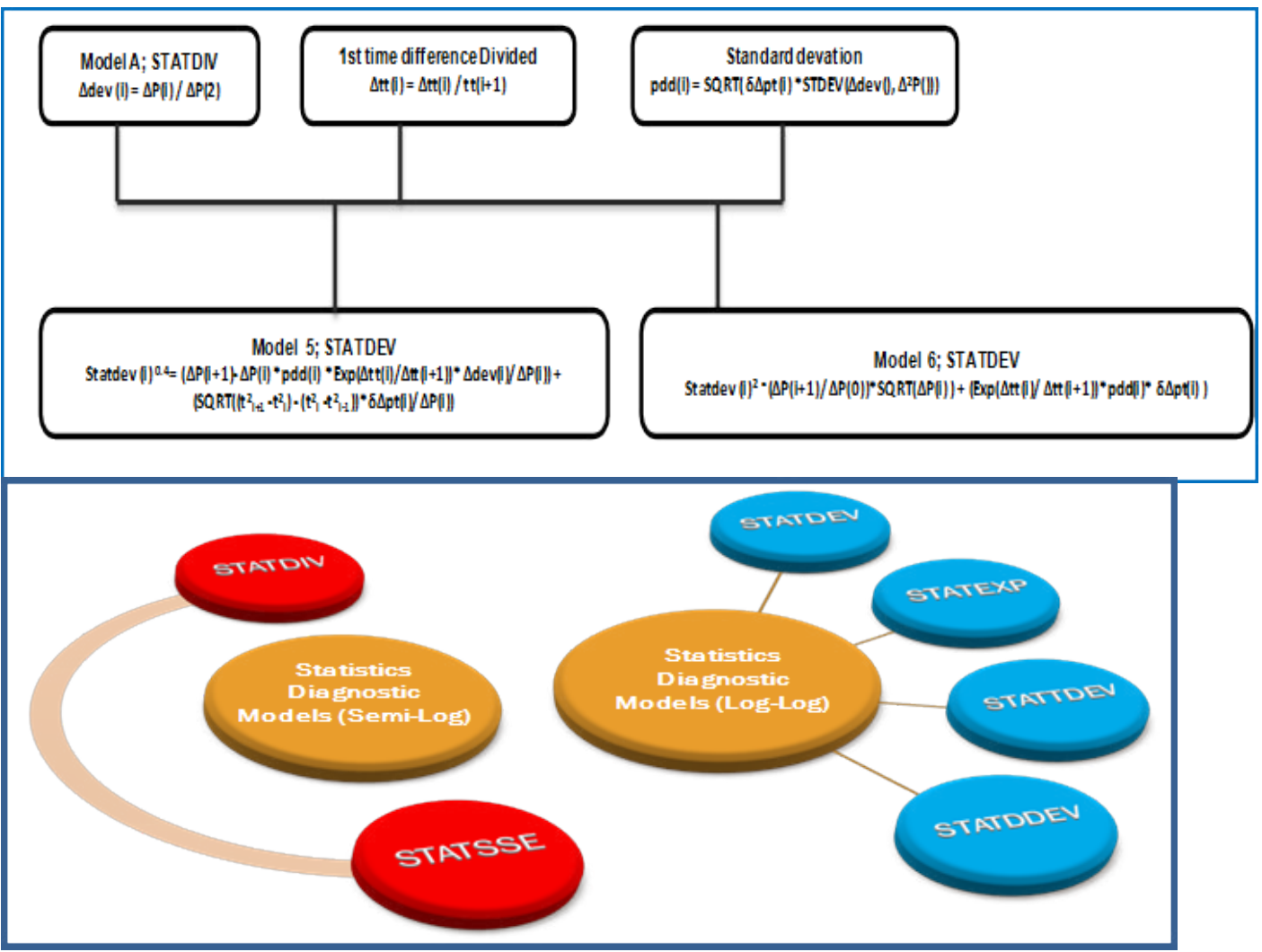

Figure2: Statistical models for flow regime identification 
Citation: Victor BT, Shi-Yi Z (2015) A New Approach in Pressure Transient Analysis Part I: Improved Diagnosis of Flow Regimes in Oil and Gas Wells. J Pet Environ Biotechnol 6: 244. doi:10.4172/2157-7463.1000244

\begin{tabular}{|c|c|}
\hline Parameters & Design Value \\
\hline Eclipse model & Black Oil \\
\hline Model dimension & $\mathbf{1 0} \times \mathbf{5}$ X 5 \\
\hline Length by Width $\mathrm{ft}$ by $\mathrm{ft}$ & $\mathbf{4 0 0} \mathbf{X} \mathbf{4 0 0}$ \\
\hline Thickness $\mathrm{ft}$ & $\mathbf{2 5 0}$ \\
\hline Permeability Kx by Ky $\mathrm{md}$ & $\mathbf{5 0 . 0}$ by $\mathbf{5 0 . 0}$ \\
\hline Porosity \% & $\mathbf{2 0}$ \\
\hline Well diameter $\mathrm{ft}$ & $\mathbf{0 . 6 5}$ \\
\hline Initial water saturation Swi \% & $\mathbf{2 2}$ \\
\hline Permeability, $\mathrm{K}, \mathrm{md}$ & $\mathbf{5 0}$ \\
\hline Gas Oil contact GOC $\mathrm{ft}$ & $\mathbf{8 8 2 0}$ \\
\hline Oil water contact OWC $\mathrm{ft}$ & $\mathbf{9 0 0 0 . 0}$ \\
\hline Initial Pressure, $\mathrm{Pi}, \mathrm{psia}$ & $\mathbf{3 6 0 0 . 0}$ \\
\hline Formation Temperature, $\mathrm{T}$, oF & $\mathbf{2 0 0 . 0}$ \\
\hline
\end{tabular}

Table 1: Reservoir and fluid data for example 1.0 for three scenarios tested

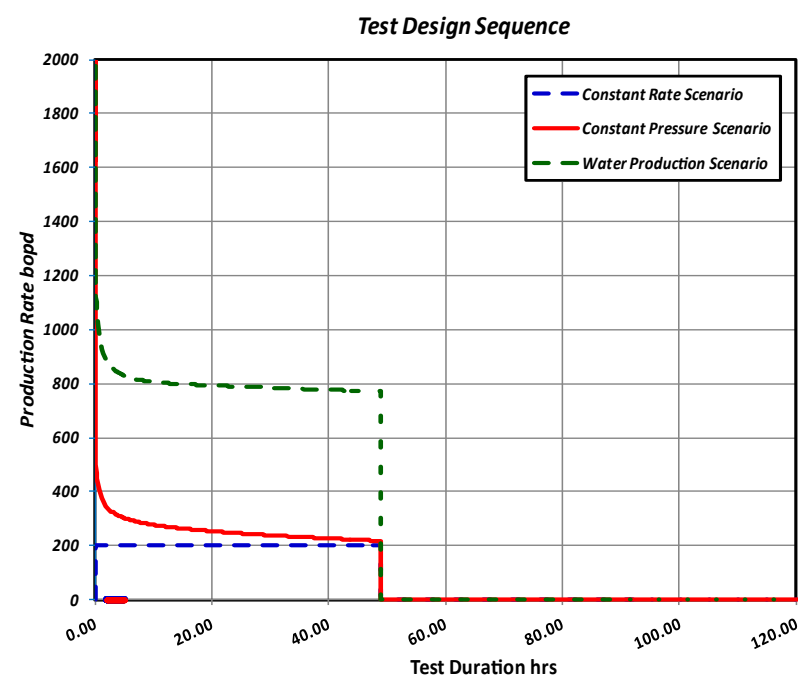

Figure 3: Production and shut-in test sequence for three scenarios (Drawdown and Build-up).

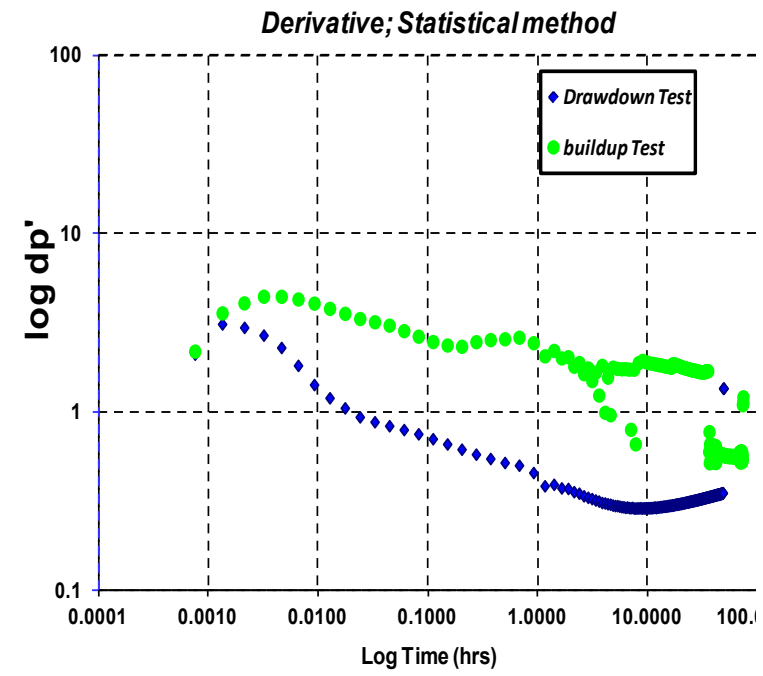

Figure 4: Statistical derivative for constant pressure scenario (buildup and drawdown).

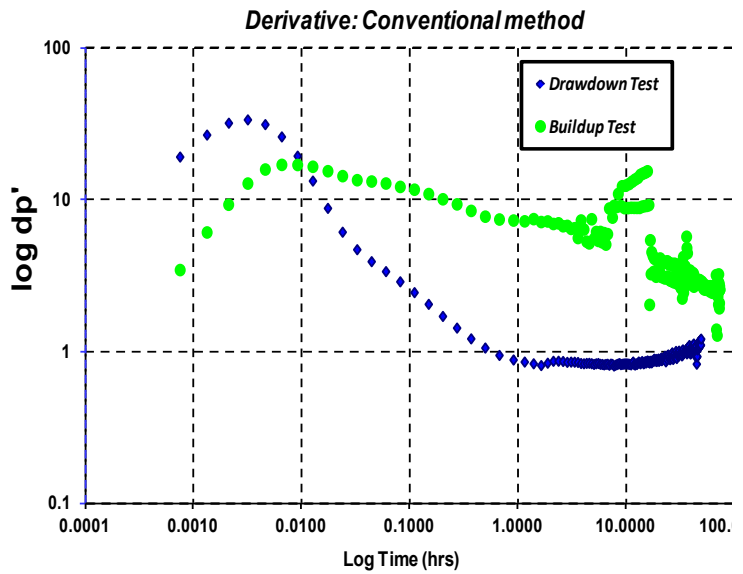

Figure 5: Conventional derivative for constant pressure scenario (buildup and drawdown).

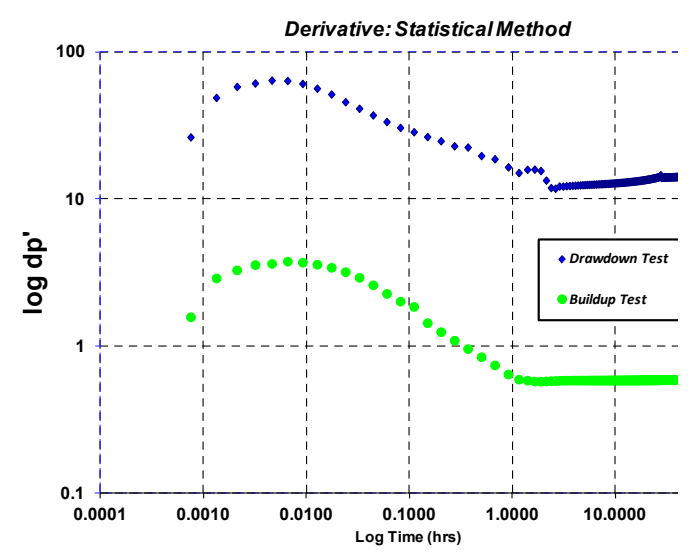

Figure 6: Statistical derivative for constant rate scenario (buildup and drawdown).

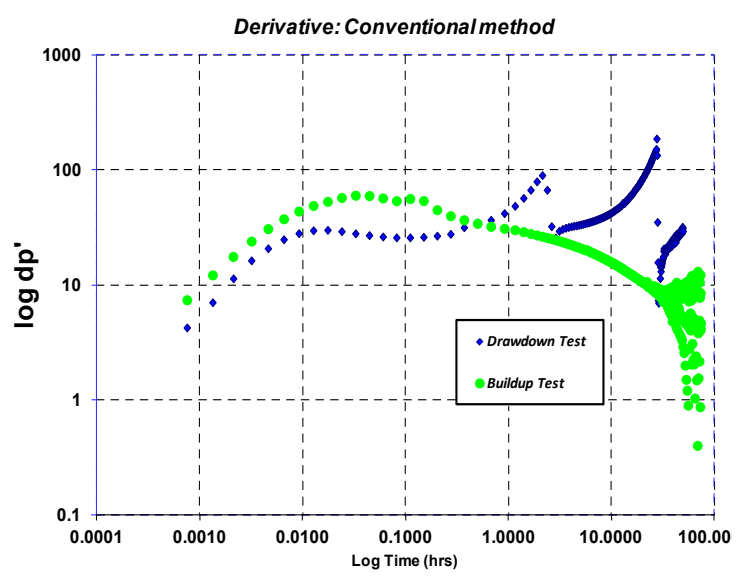

Figure 7: Conventional derivative for constant rate scenario (buildup and drawdown). 


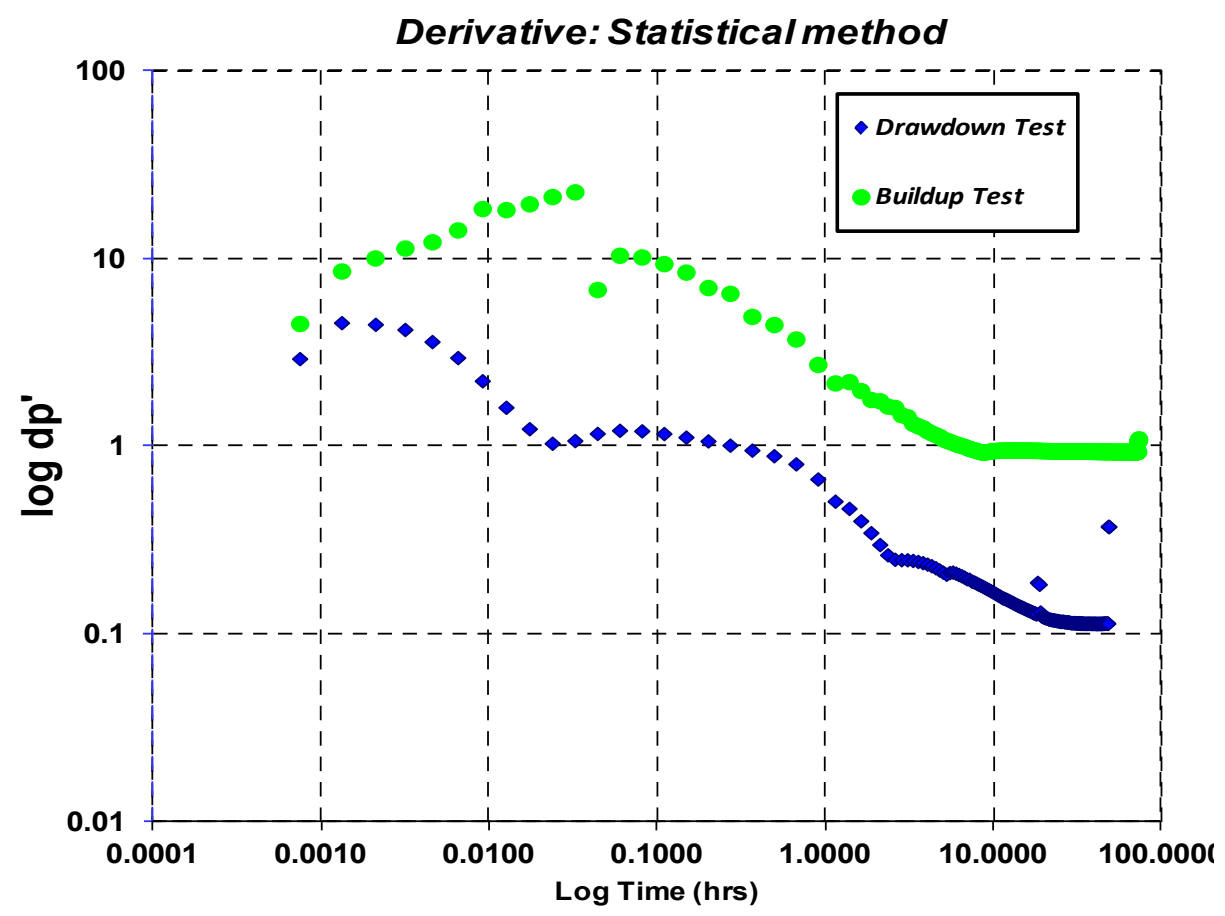

Figure 8: Conventional derivative for constant rate scenario (buildup and drawdown)

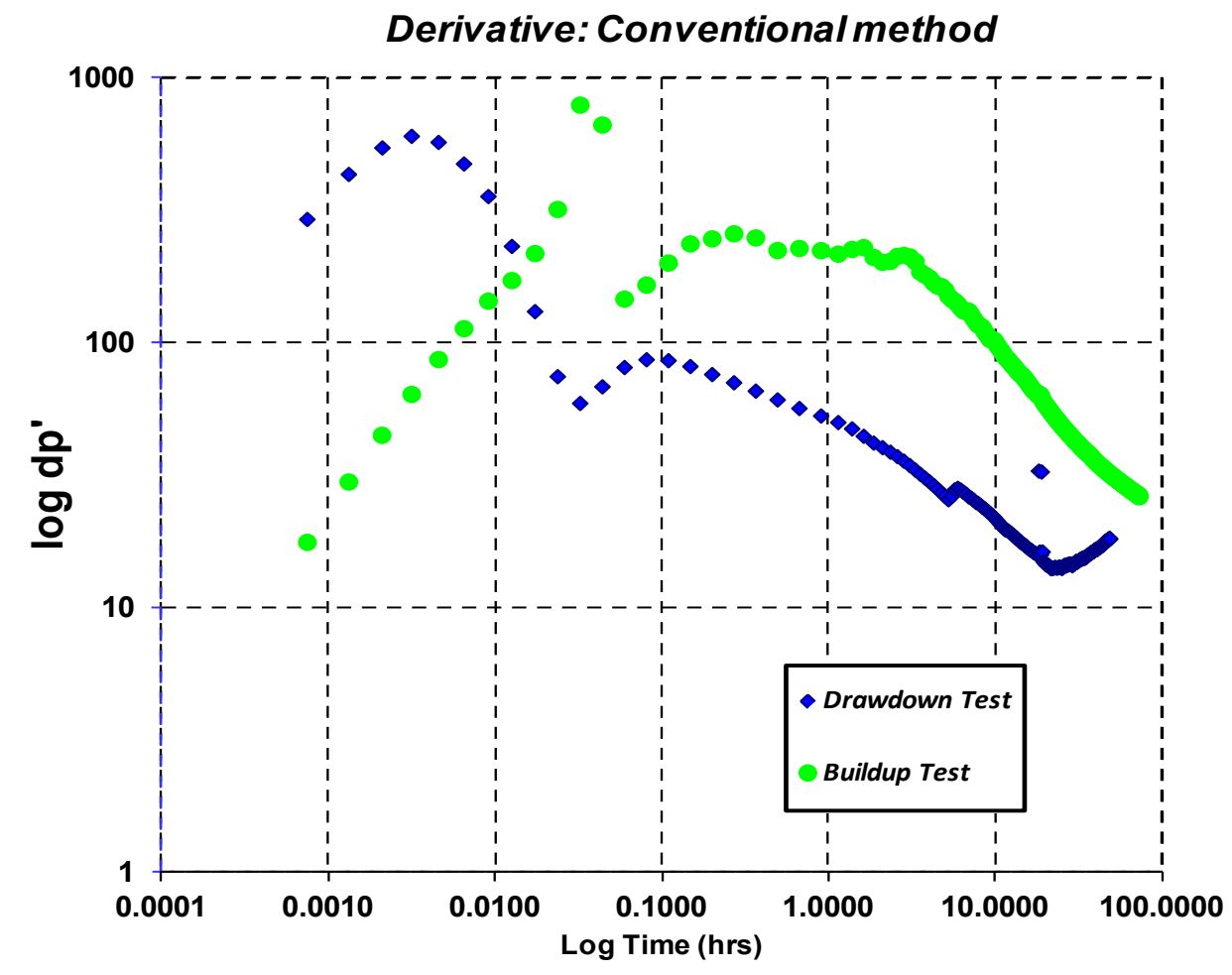

Figure 9: Conventional derivative for high water production scenario (buildup and drawdown). 
Citation: Victor BT, Shi-Yi Z (2015) A New Approach in Pressure Transient Analysis Part I: Improved Diagnosis of Flow Regimes in Oil and Gas Wells. J Pet Environ Biotechnol 6: 244. doi:10.4172/2157-7463.1000244

\section{Conclusion}

The following inference was drawn from the three scenarios reviewed;

- For constant pressure, constant rate conditions and well with high water production, the statistical derivatives display distinctive radial flow fingerprint with clear radial stabilisation at high degree of accuracy.

- In all three scenarios, it has shown that, the drawdown fingerprint can be replicated in the build-up pressure responses, hence a good match of the data.

- It also demonstrated that for high water production well, radial stabilization can be identified for permeability estimation without smoothing the data.

- The approach also reduces the pressure noise in the radial flow period for better interpretation of flow regimes.

- The model helps to identify/or diagnose possible reservoir flow regimes for reservoir description and also acts as a checkbox/ support to the pressure derivative approach in PTA.

\section{Summary of statistical versus conventional derivatives for different reservoir conditions}

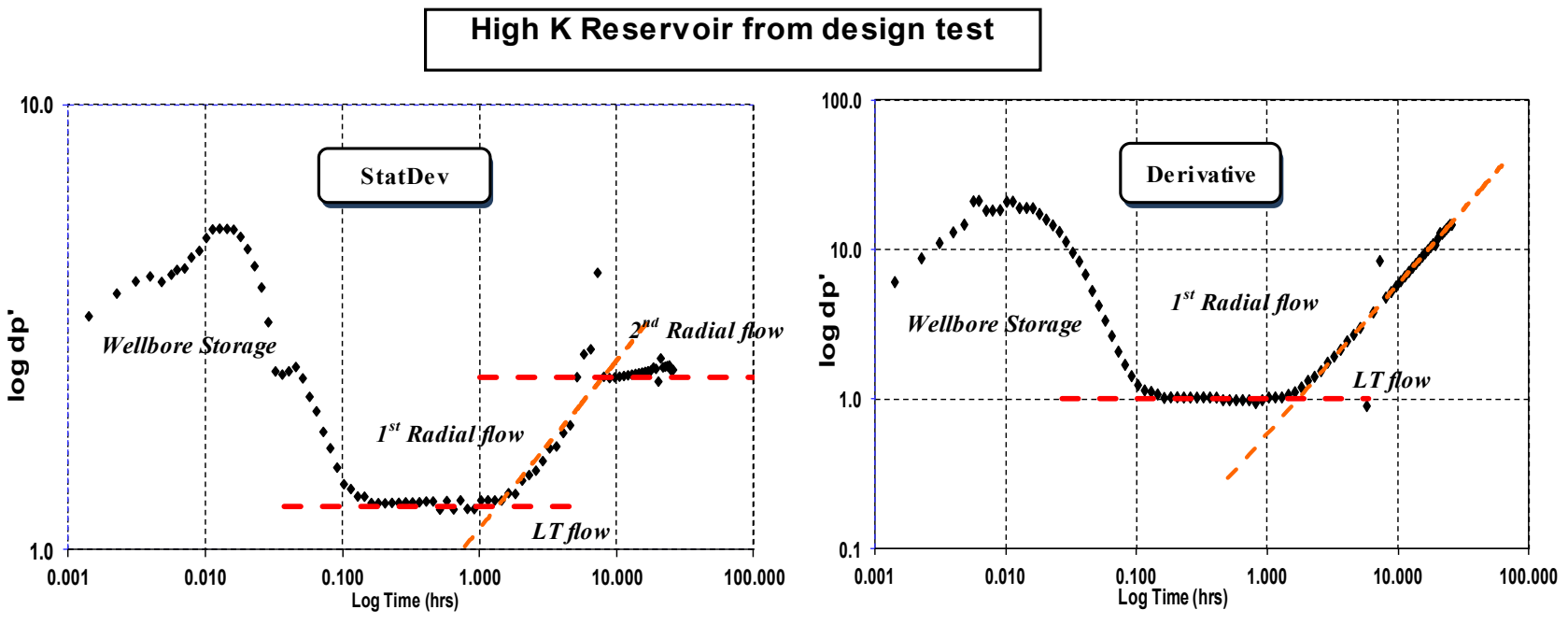

Figure 10: Comparisons of derivative and StatDev diagnostics approach.
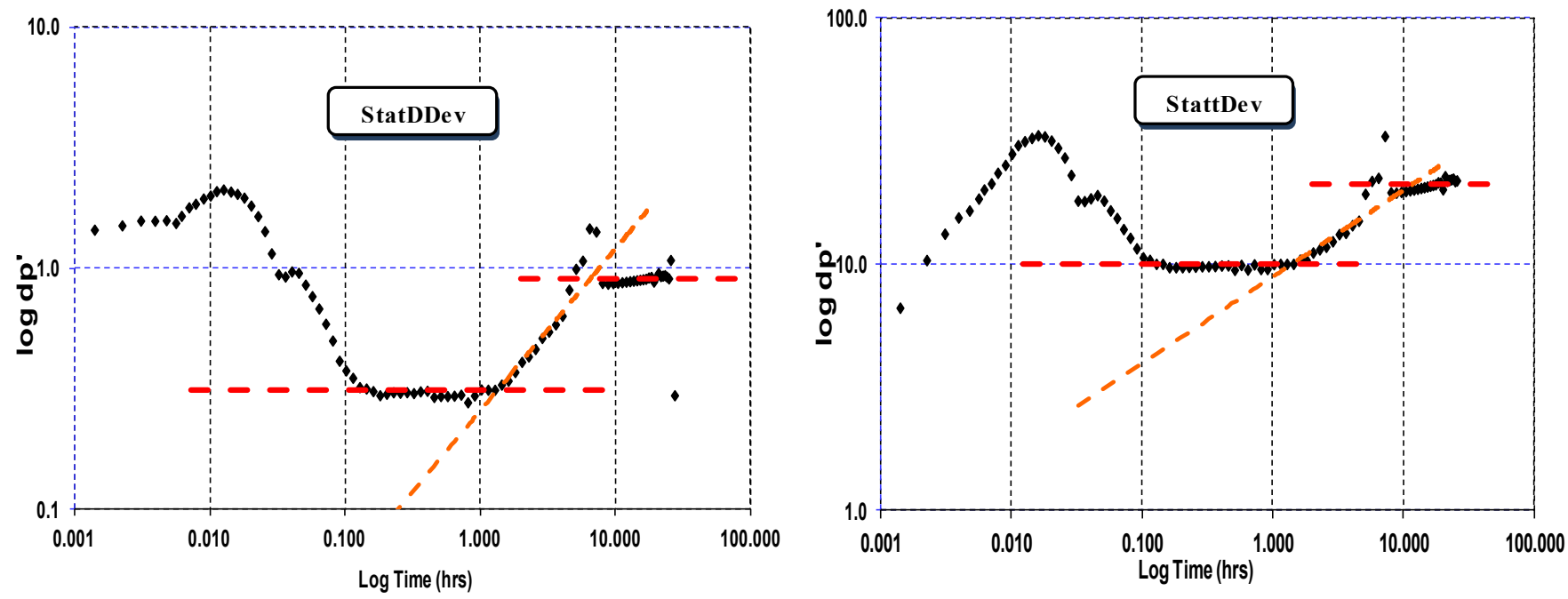

Figure 11: Comparisons of StatDDev and StattDev diagnostics approach. 

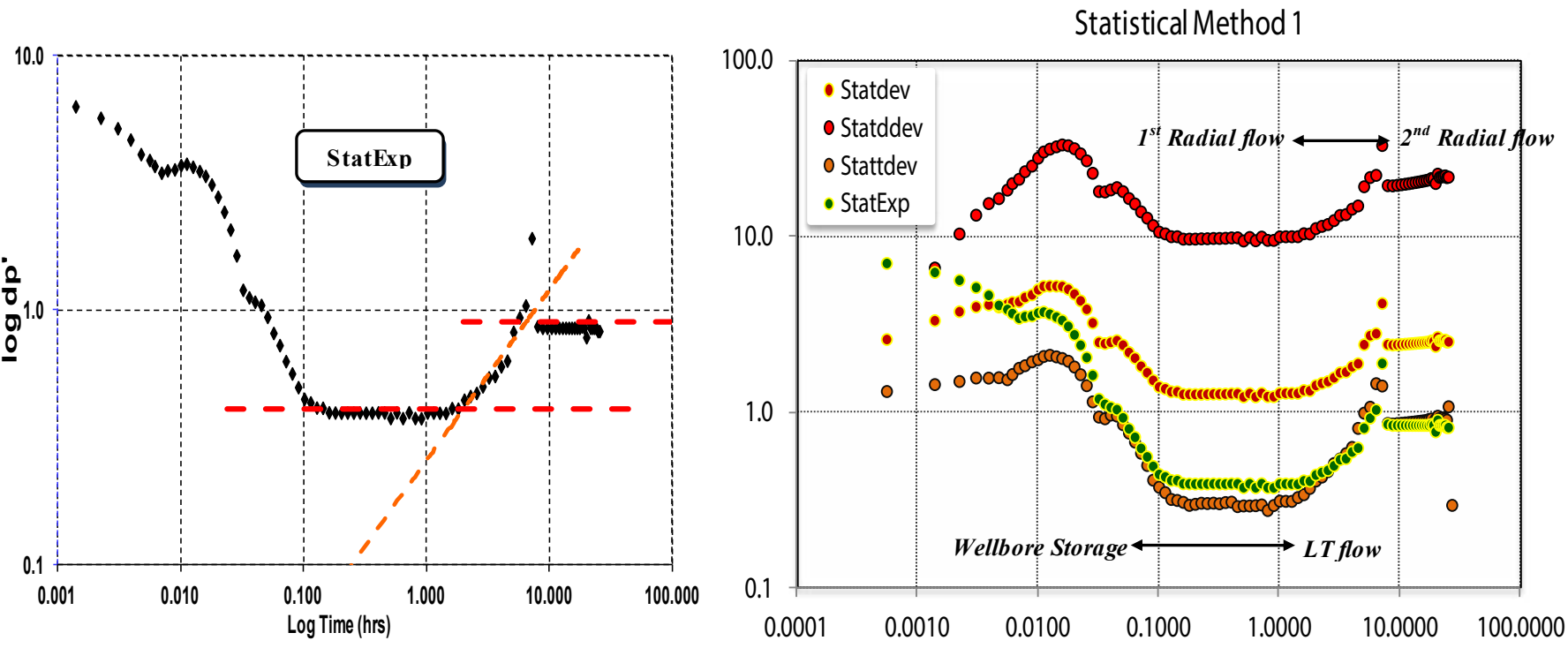

Figure 12: StatExp for high $\mathrm{K}$ with undefined boundary response and all statistical models for reservoir model diagnosis.
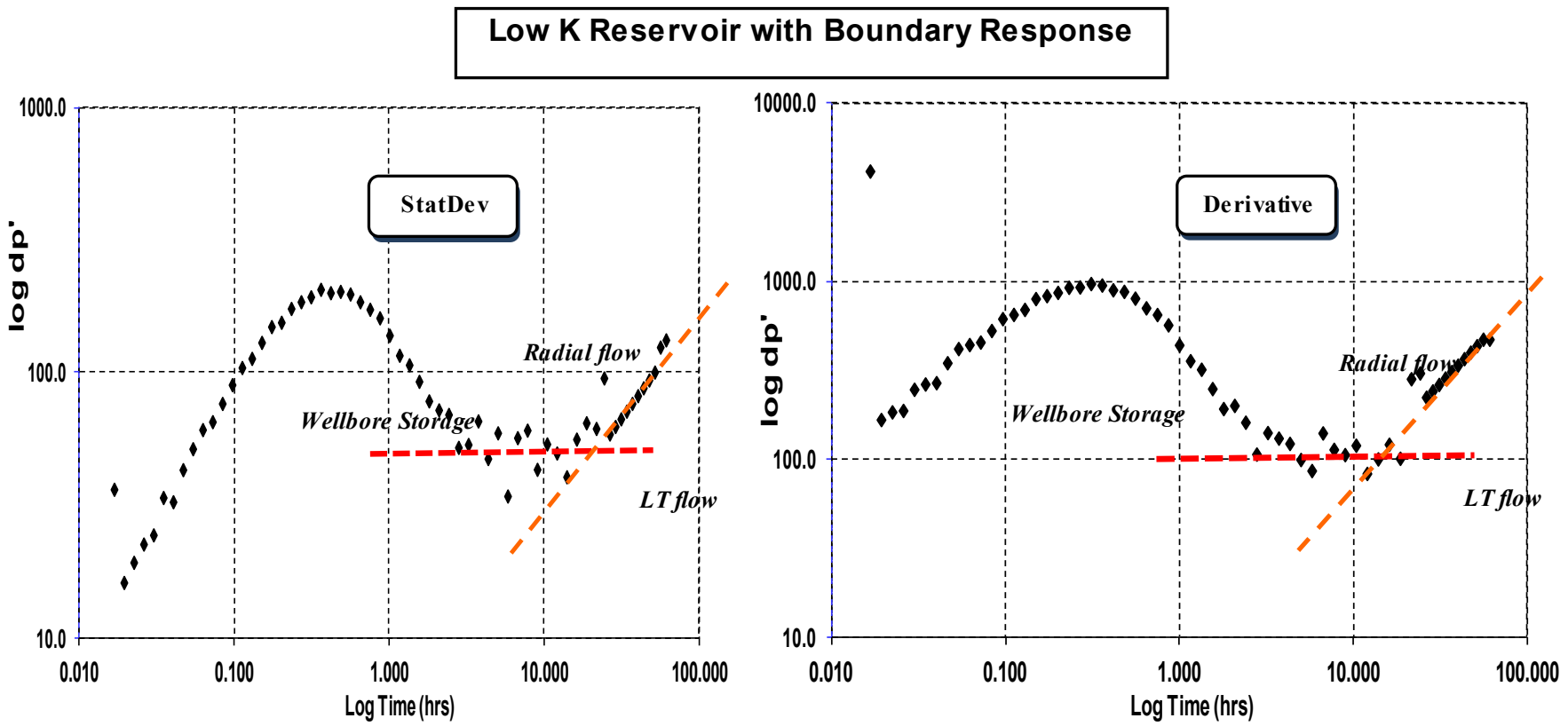

Figure 13: Comparisons of derivative and StaDev plot for reservoir model diagnosis. 

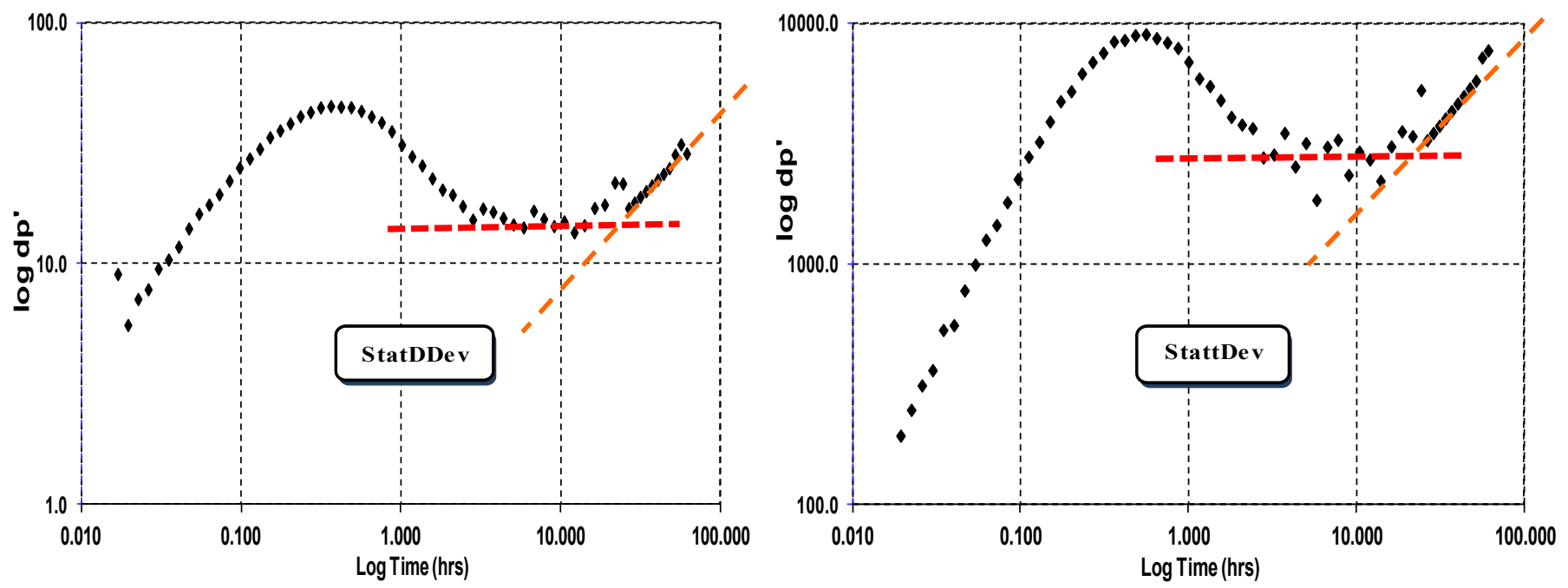

Figure 14: Comparisons of StatDDev and StattDev diagnostics approach.
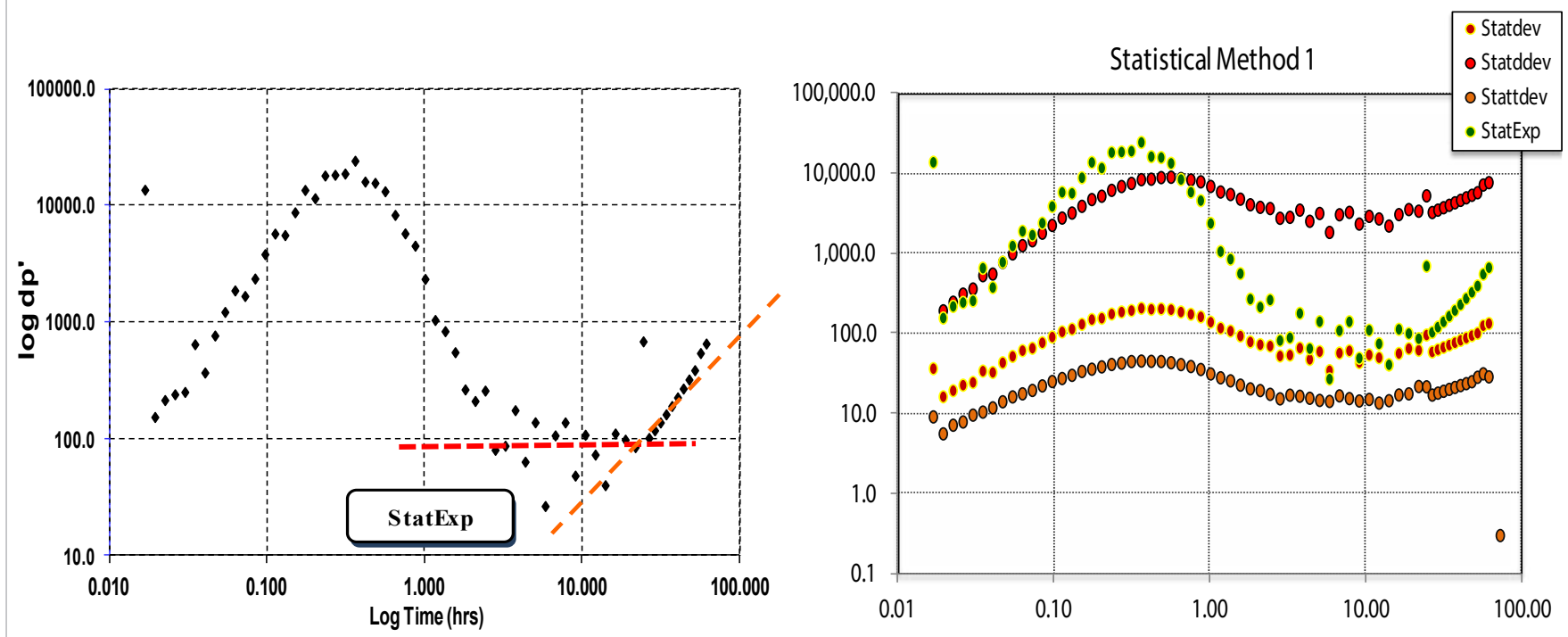

Figure 15: StatExp for low $\mathrm{K}$ in a closed boundary response and all statistical models for reservoir model diagnosis. 

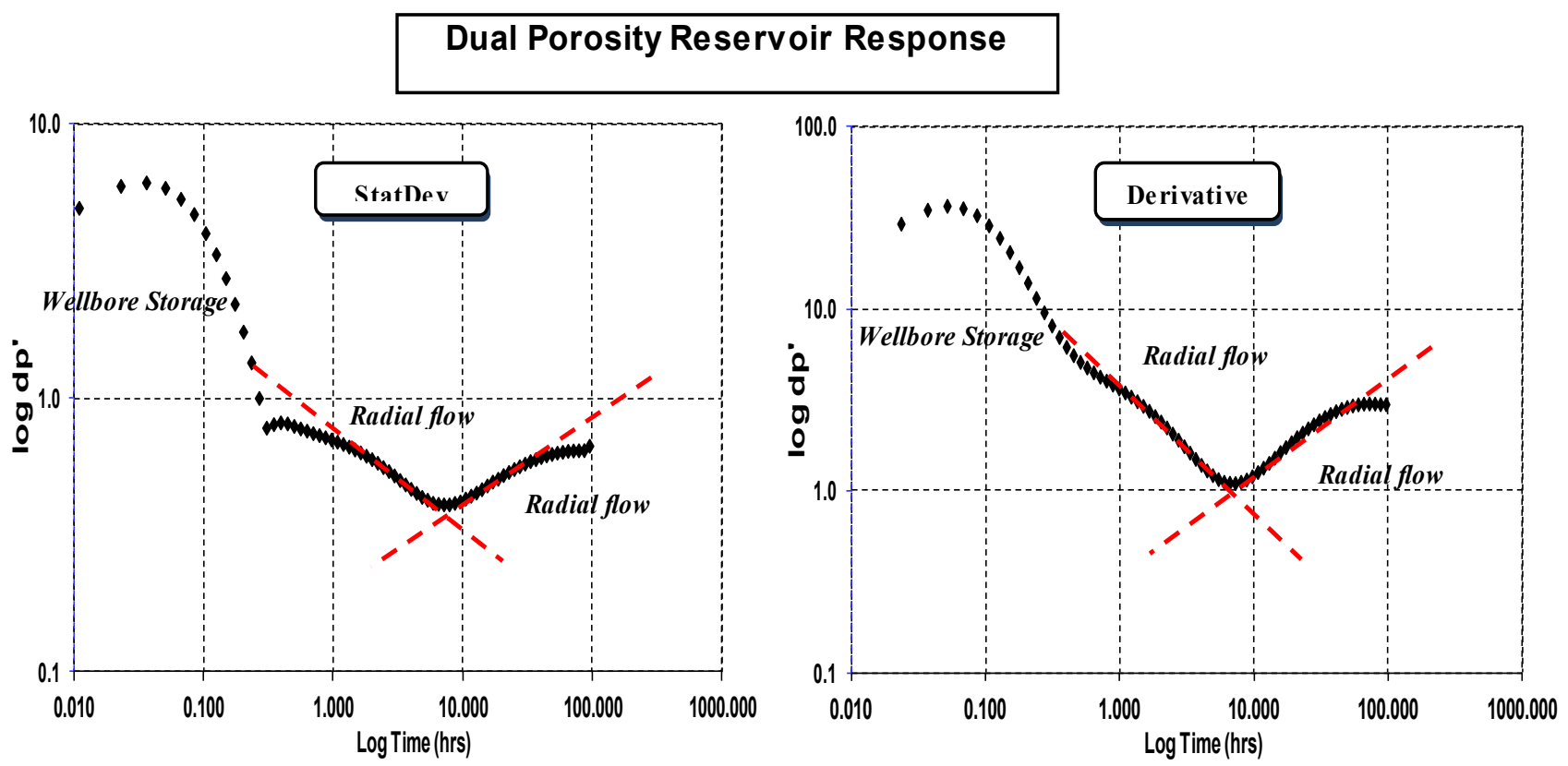

Figure 16: Comparisons of derivative and StatDev diagnostics approach.
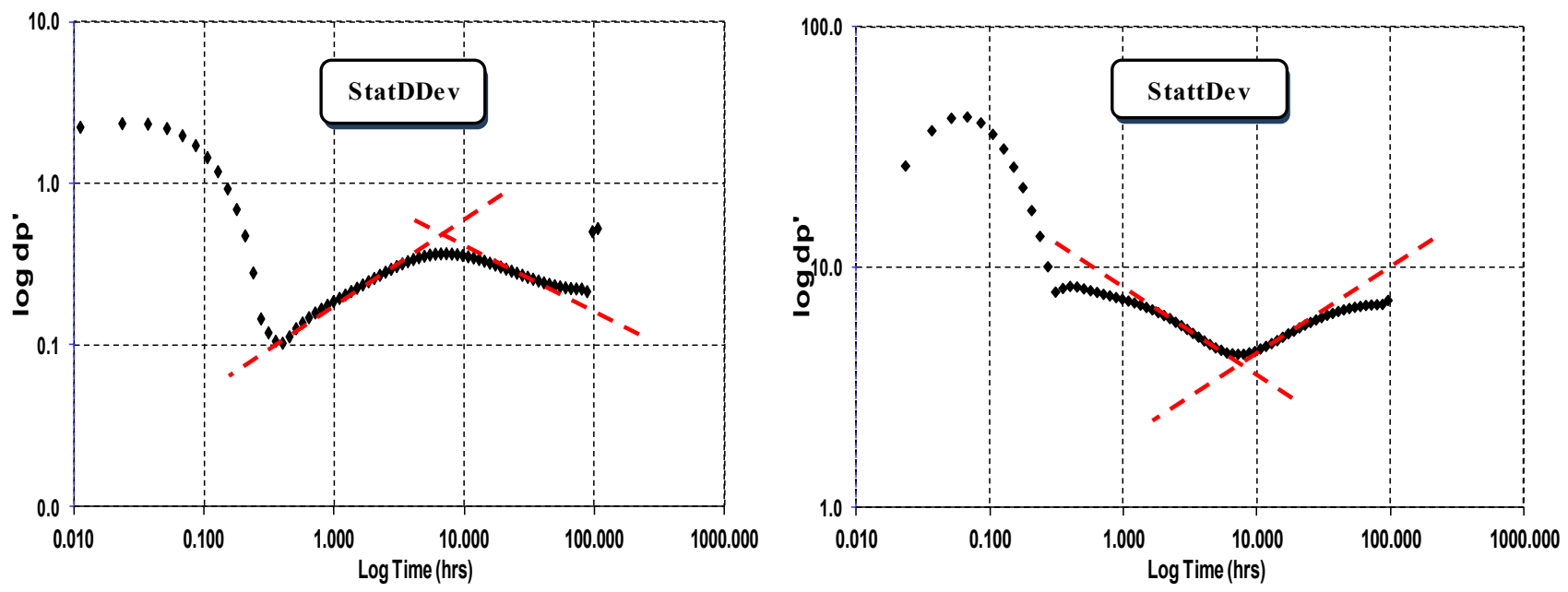

Figure 17: Comparisons of StatDDev and StattDev diagnostics approach. 

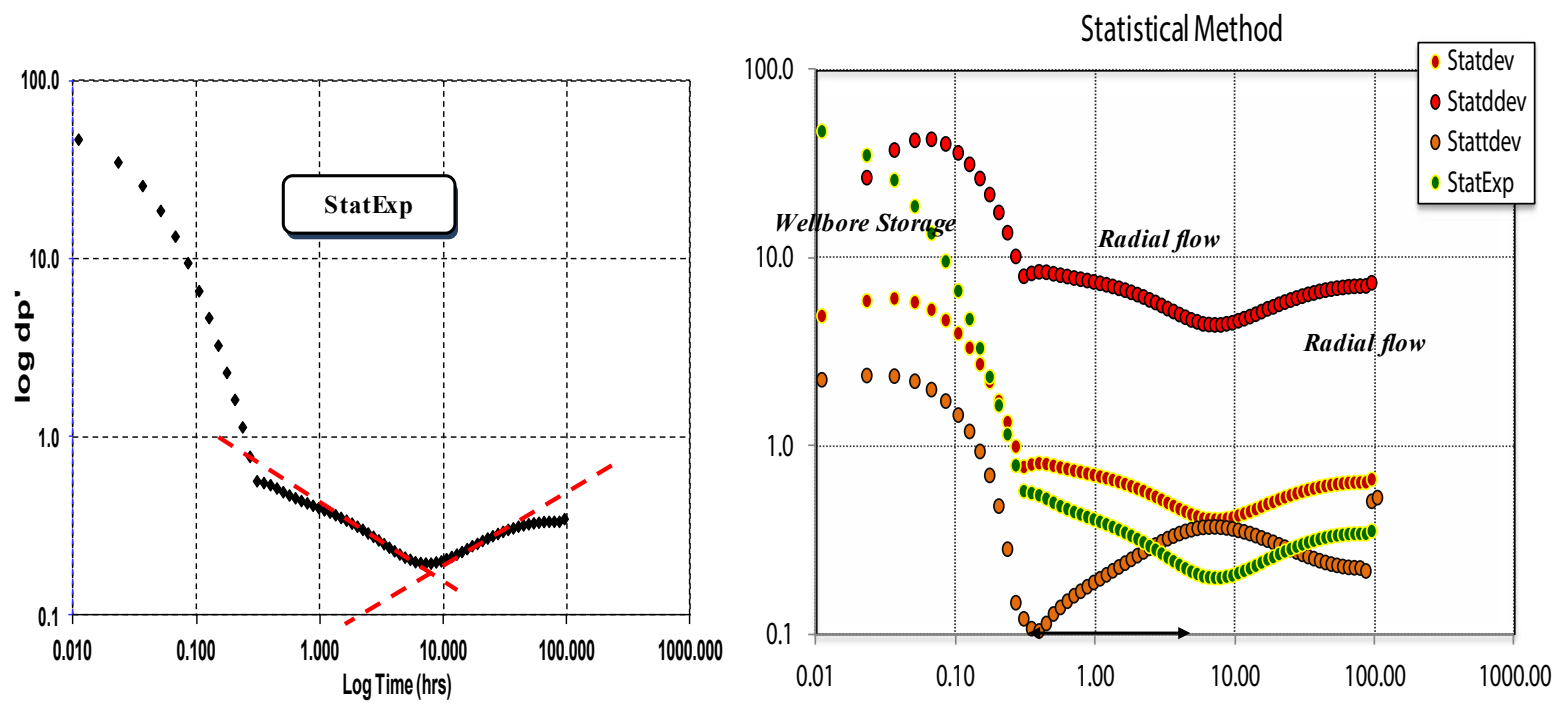

Figure 18: StatExp for low $\mathrm{K}$ in a closed boundary response.

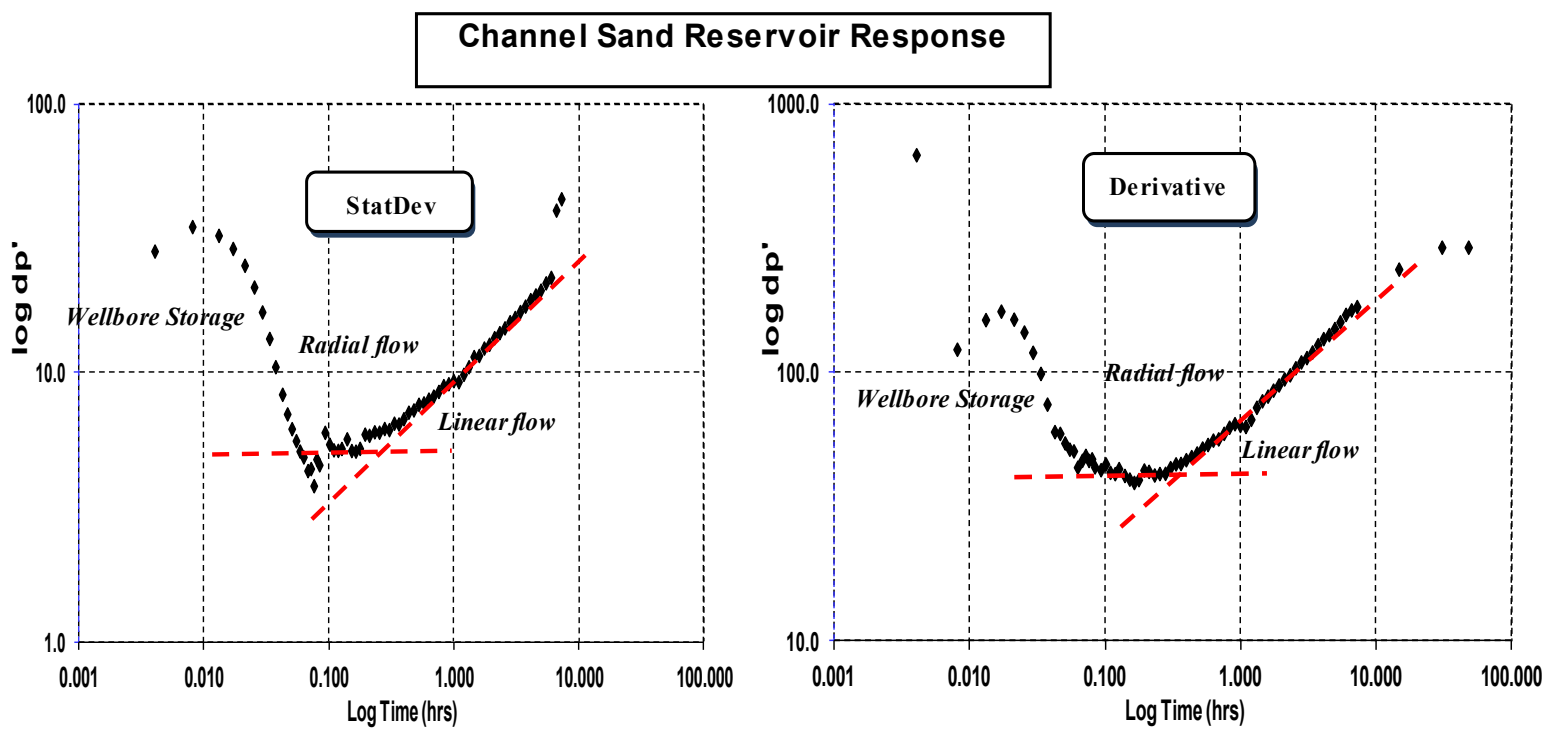

Figure 19: Comparisons of derivative and StatDev diagnostics approach. 

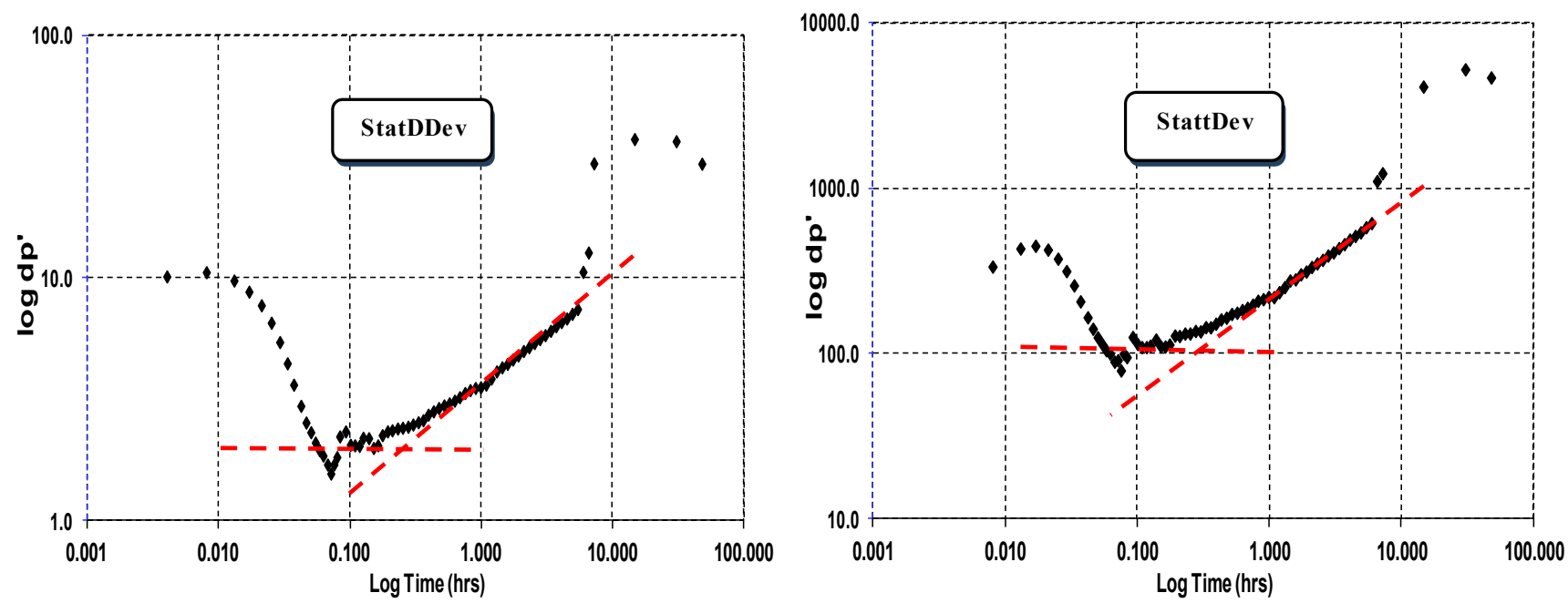

Figure 20: Comparisons of StatDDev and StattDev diagnostics approach.
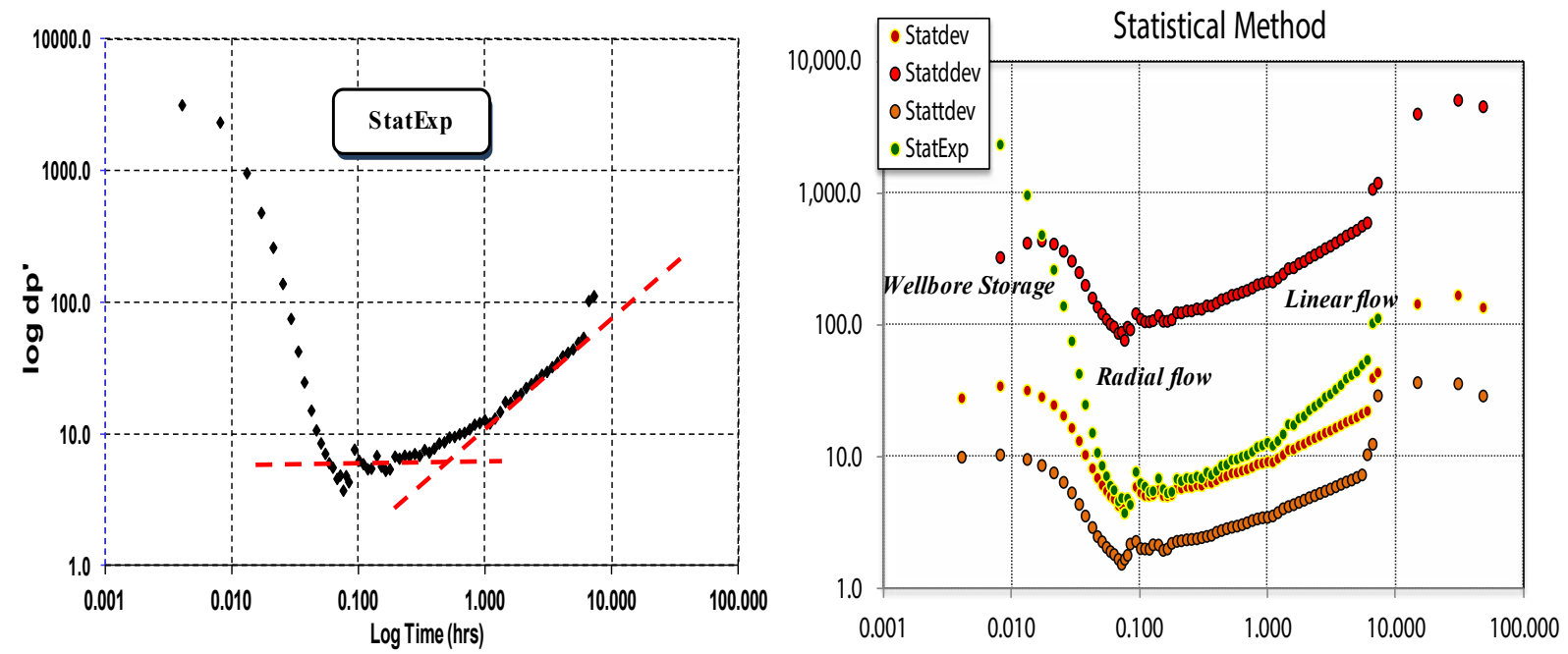

Figure 21: StatExp for low $\mathrm{K}$ in a closed boundary response. 


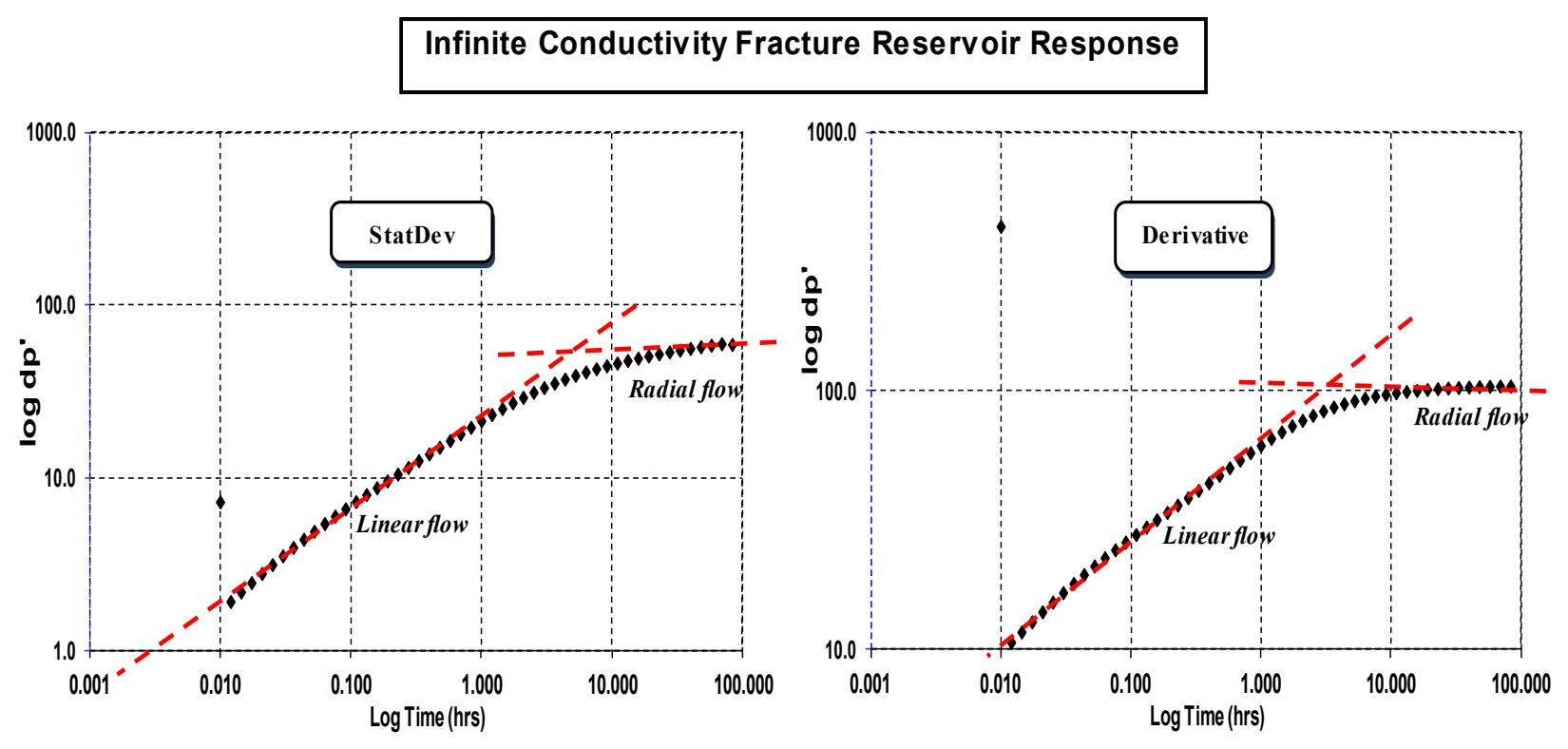

Figure 22: Comparisons of derivative and StatDev diagnostics approach.
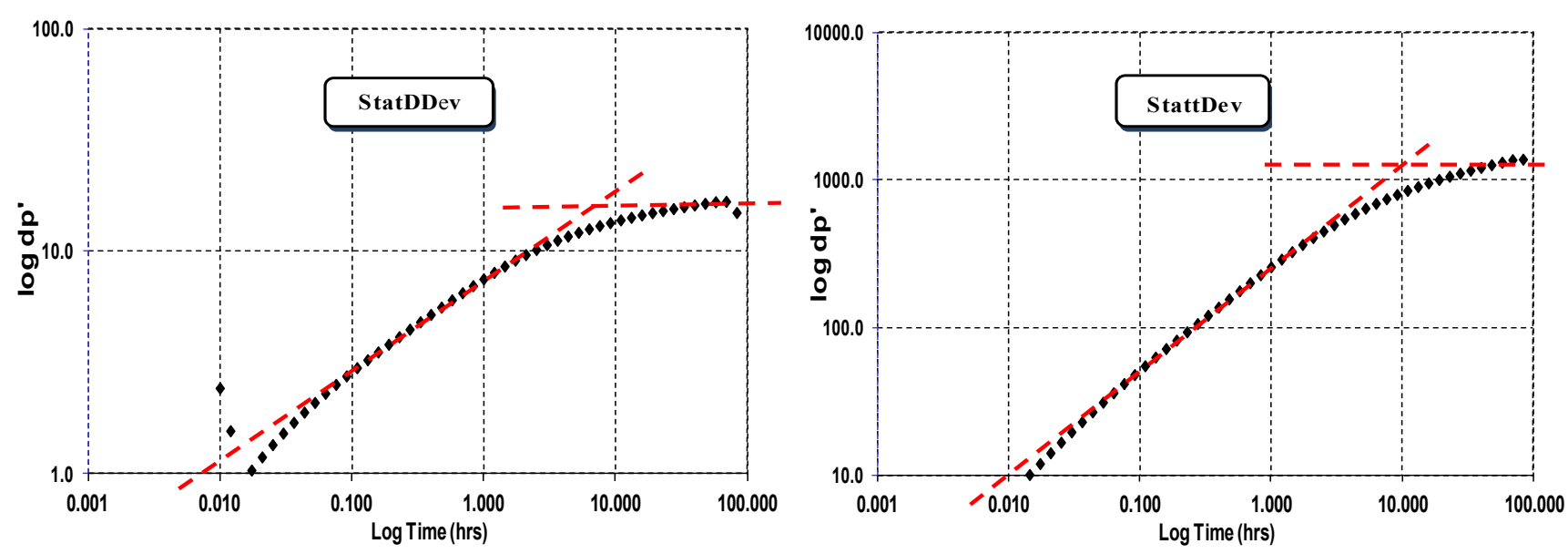

Figure 23: Comparisons of StatDDev and StattDev diagnostics approach. 

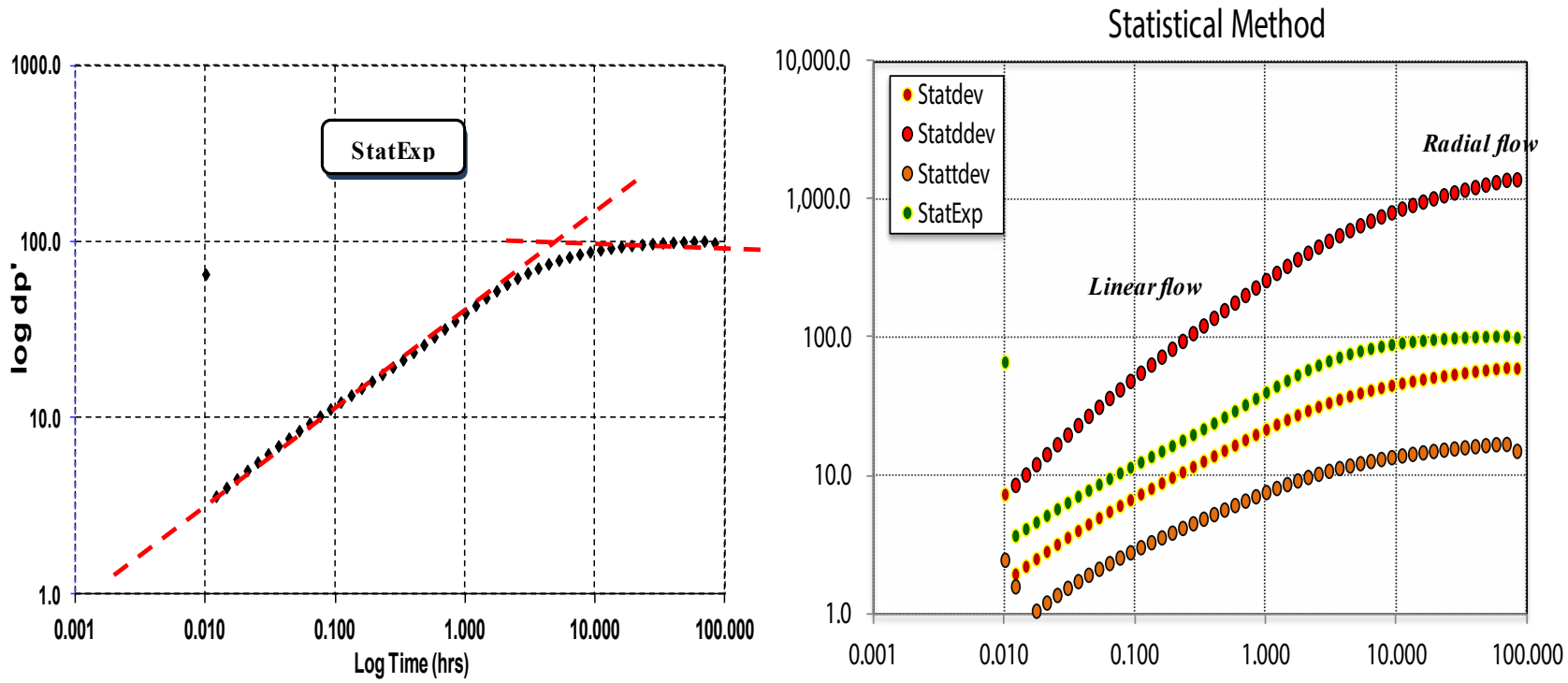

Figure 24: StatExp for low $\mathrm{K}$ in a closed boundary response.

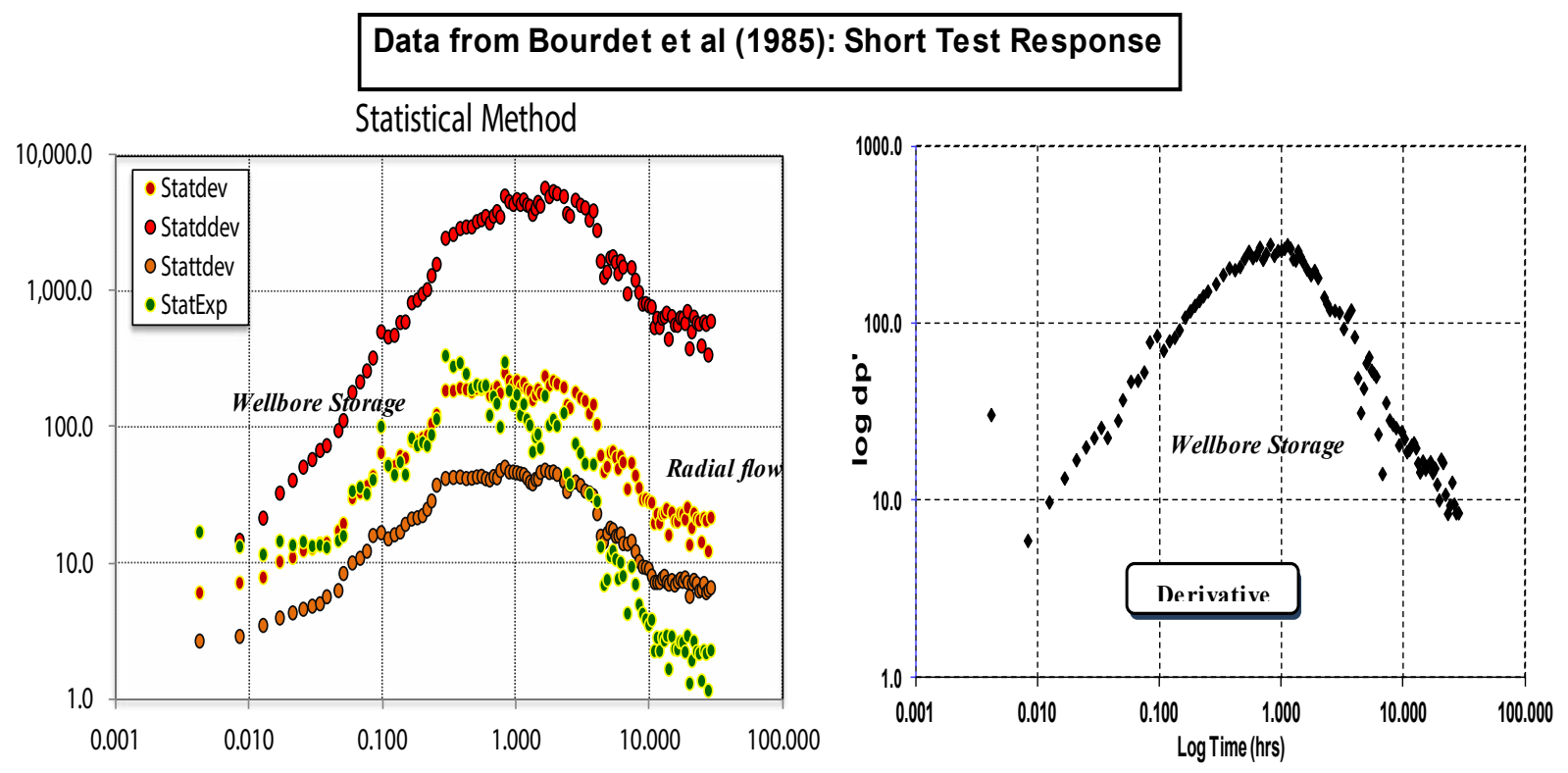

Figure 25: All statistical models for reservoir model diagnosis and StatExp for low $\mathrm{K}$ in a closed boundary response. 
Citation: Victor BT, Shi-Yi Z (2015) A New Approach in Pressure Transient Analysis Part I: Improved Diagnosis of Flow Regimes in Oil and Gas Wells. J Pet Environ Biotechnol 6: 244. doi:10.4172/2157-7463.1000244

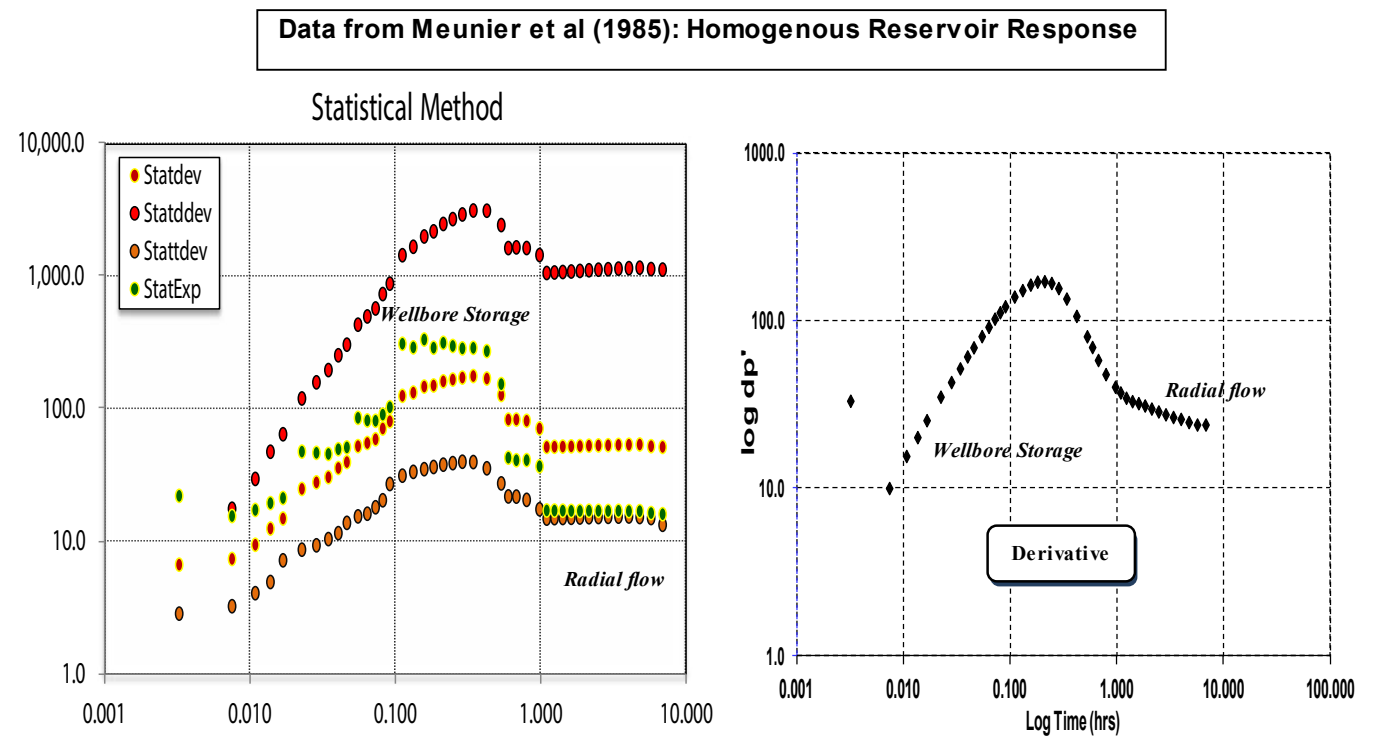

Figure 26: All statistical models for reservoir model diagnosis and StatExp for low $\mathrm{K}$ in a closed boundary response.

\section{References}

1. Kristopher Lk (2006) Laplace transform analytic element method for transient groundwater flow simulation. The University of Arizona, Tucson.

2. Weiland J (2008) Shell Exploration \& Production. In: Azari M, Suparman (eds.) Case History Review of the Applocation of Pressure Transient Testing and Production Logging in Monitoring the Performance of the Mars Deep water. Gulf of Mexico Field, SPE.

3. Nnadi M (2004) Laser Engineering and Resources Consultants Limited. In Neuman SP, Di Federico V (eds.) Multifaceted nature of hydrologic scaling and its interpretation. Reviews of Geophysics 41: 1014

4. Freddy HE, Surcolombiana U, Navarrete JM (2004) Evaluation of Pressure Derivative Algorithms for Well-Test Analysis. SPE International Thermal Operations and Heavy Oil Symposium and Western Regional Meeting, Bakersfield, California.

5. Kamal MM, Pan Y, Landa JL, Chevron Corp, Thomas OO, et al. (2005) Numerical well testing: A Method To Use Transient Testing Results in Reservoir Simulation. SPE Annual Technical Conference and Exhibition, Dallas, Texas.

6. Jackson RR, Banerjee R, Schlumberger (2000) Advances in multiplayer reservoir testing and analysis using numerical well testing and reservoir simulation. SPE.

7. Landa JL, Horne RN, Kamal MM, Jenkins CD (2000) Reservoir Characterization Constrained to Well-Test Data: A Field Example. SPE Reservoir Eval and Eng 3: $325-334$.

8. Zakirov SN, Indrupskiy IM, Zakirov ES, Anikeev DP, Tarasov Al, et al. (2006) New Approaches in well Testing. Institute of the Russian Academy of Sciences. SPE. SPE Europec/EAGE Annual Conference and Exhibition, Vienna, Austria.

9. Muskat M (1934) The flow of compressible fluid through porous media and some problems in heat conduction. Journal of Applied Physics 5.

10. Theis CV (1935) The relation between the lowering of the piezonmetric surface and the rate and duration of discharges of well using ground-water storage. Trans 519-524.

11. Miller CC, Dyes AB, Hutchinson CA (1950) Estimation of $k$ and Reservoir Pressure from Bottom Hole Pressure Buildup Characteristics. Trans aime 189: 91-104.

12. Agarwal RG, AL-Hussainy R, Ramey HJJR (1970) An investigation of wellbore and skin effect in unsteady liquid flow: I. Analytical treatment. SPE J 10: 279-290.

13. Ramey HJ, Kruger P (1979) Proceedings, Fifth Annual workshop On Geothermal Reservoir Engineering. Stanford, California.

14. Gringarten AC, Bourdet DP, Landel PA, Kniazeff VJ (1979) A Comparison Between Different Skin and Wellbore Storage Type Curve for Early Time Transient Analysis. SPE Annual Technical Conference and Exhibition, Las Vegas, Texas.

15. Bourdet D, Whittle TM, Douglas AA, Pirard YM (1983) A new set of type curves simplifies well test analysis. World Oil 196: 95-106.

16. Zheng SY (2006) Fighting against non-unique solution problems in heterogeneous reservoirs through numerical well testing. Asia Pacific Oil and Gas Conference and Exhibition. Adelaide, Australia.

17. Horne RN, Temeng KO (1982) Recognition and Location of Pinchout Boundaries by Pressure Transient Analysis. Journal of Petroleum Technology.

18. Ayestaran LC, Nurmi RD, Shehab GAK, Elsi WS (1989) Well Test Design and Interpretation Improved by Integrated Well Testing and Geological Efforts. SPE.

19. Massonnat GJ, Bandiziol D (1991) Interdependence between Geology and Well Test Interpretation. SPE Annual Technical Conference and Exhibition. Dallas, Texas.

20. Du KF, Stewart G (1994) Reservoir Description from Well Test Interpretation North Sea Oil and Gas Reservoir - III 339-356.

21. Zheng SY (1997) Well Testing and Characterisation of Meandering Fluvia Channel Reservoirs. Heriot-Watt University. Petroleum Engineering 226.

22. Jalali J, Mohaghegh SD, Gaskari R (2006) Identifying Infill Locations and Underperformer Wells in Mature Fields Using Monthly Production Rate Data, Carthage Field, Cotton Valley Formation, Texas. SPE pp: 1-7.

23. Victor B, Biu EO, Onyekonwu MO (2009) Statistical Diagnosis (VEMST) of Flow Regime; Alternative to Pressure Derivative Approach in Pressure Transient Analysis-Part I. SPE, Nigeria Annual International Conference and Exhibition Abuja, Nigeria.

24. Ehlig-Economides CA, Schlumberger HP, Saga SV (1994) Guidelines simplify well test interpretation. Oil and Gas Journal.

25. Horne RN (1995) Modern welltest analysis: a computer-aided approach Petroway pp: 1-257. 
Citation: Victor BT, Shi-Yi Z (2015) A New Approach in Pressure Transient Analysis Part I: Improved Diagnosis of Flow Regimes in Oil and Gas Wells. J Pet Environ Biotechnol 6: 244. doi:10.4172/2157-7463.1000244

Page 17 of 17

26. Plummer EA (2000) Time series forecasting with feed-forward neural networks: guidelines and limitations. Master of Science Thesis, University of Wyoming, Laramie, Wyoming.

27. Automate Windowstm Application Welltest Software (1995) Test and Examples of well test. Petroway, Palo Alto, California.

28. Onyekonwu MO (1997) General Principle of bottomhole pressure tests. Laser Engineering Consultant, Port Harcourt pp: 56-58.

29. Priestley MB (1981) Spectral Analysis and Time Series. Academic Press.
30. http://www.itl.nist.gov/div898/handbook/pmc/section4/pmc442.html

31. http://en.wikipedia.org/wiki/Hydrogeology

32. Losada Hydrocarbon Services Ltd (2004) Evaluation of Pressure Derivative Algorithms for Well-Test Analysis. SPE 86936.

33. University of Port Harcourt (2004) Numerical Welltest Analysis.

34. http://www.itl.nist.gov/div898/handbook/pmc/section4/pmc442.htm 